Pontifícia Universidade $_{\text {Do Rio de Janeiro }}$

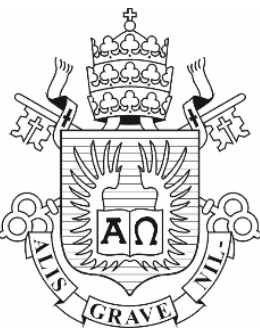

Lucio Cerqueira de Amorim Araujo

\title{
Avaliação da Eficiência Operacional de Terminais Aquaviários de Carga Líquida
}

Dissertação apresentada como requisito parcial para obtenção do grau de Mestre pelo Programa de Pós-graduação em Engenharia de Produção do Departamento de Engenharia Industrial da PUC-Rio.

Orientador: Prof. Silvio Hamacher Co-orientador: João Carlos Correia Baptista Soares de Mello 


\section{Pontifícia Universidade Católica \\ DO RIO DE JANEIRO}

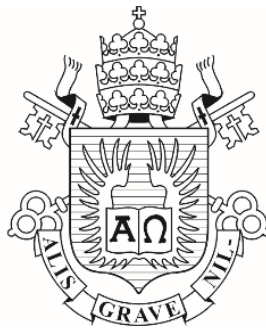

Lucio Cerqueira de Amorim Araujo

\section{Avaliação da Eficiência Operacional de Terminais Aquaviários de Carga Líquida}

Dissertação de Mestrado

Dissertação apresentada como requisito parcial para obtenção do grau de Mestre pelo Programa de Pósgraduação em Engenharia Produção da PUC-Rio. Aprovada pela Comissão Examinadora abaixo assinada.

Prof. Sivio Hamacher Orientador Departamento de Engenharia Industrial-PUC-Rio

Prof. João Carlos Correa Baptista Soares de Mello Co-orientador Universidade Federal Fluminense-UFF

Prof. José Eugenio Leal Departamento de Engenharia Industrial-PUC-Rio

Prof. Hugo Miguel Varela Repolho Departamento de Engenharia Industrial-PUC-Rio

Prof. José Eugenio Leal Coordenador Setorial do Centro Técnico Científico - PUC-Rio 
Todos os direitos reservados. É proibida a reprodução total ou parcial do trabalho sem autorização da Universidade, do autor e do orientador.

\title{
Lucio Cerqueira de Amorim Araujo
}

Graduou-se em Engenharia Mecânica na Universidade do Estado do Rio de Janeiro (UERJ) em 1999. Especializouse em Marketing em 2001 pela Fundação Getúlio Vargas (FGV). Funcionário da Petrobras desde outubro de 2006, trabalha no setor de logística, acompanhando as movimentações de produtos claros.

Ficha Catalográfica

\begin{abstract}
Araujo, Lucio Cerqueira de Amorim
Avaliação da Eficiência Operacional de Terminais Aquaviários de Carga Líquida/Lucio Cerqueira de Amorim Araujo; orientador: Silvio Hamacher, co-orientador: João Carlos Correia Baptista Soares de Mello. : Rio de Janeiro: PUC, Departamento de Engenharia Industrial - 2015
\end{abstract}

$88 \mathrm{f} . ; 30 \mathrm{~cm}$

Dissertação (mestrado) - Pontifícia Universidade Católica do Rio de Janeiro (PUC-RJ), Departamento de Engenharia Industrial, 2015

Incluí referências bibliográficas.

1.Engenharia Industrial - Teses. 2. Cadeia de Suprimentos da Indústria de Petróleo. 3.Portos. 4. Desempenho. 5.Data Envelopment Analysis. I. Hamacher Silvio; Soares de Mello, João Carlos B. II. Pontifícia Universidade Católica do Rio de Janeiro. Departamento de Engenharia Industrial. III. Título 


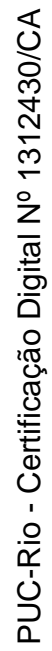

Dedico à minhas filhas Ana Clara, Maria Vitoria (in memorian) e Carolina. 


\section{Agradecimentos}

Em primeiro lugar à Deus por me proporcionar a vida, fé e sabedoria.

Em especial à minha esposa Alessandra que me incentivou em todos os momentos, que muito contribuiu para a finalização desta dissertação.

Em especial aos meus queridos pais, Jose e Marli, que sempre estiveram presentes e mostraram a importância dos estudos para a minha vida.

Ao meu orientador Silvio Hamacher por todo suporte e ensinamento durante o período do mestrado.

Ao meu co-orientador João Carlos Soares de Mello pela dedicação, disponibilidade, e fundamental participação.

Aos membros da banca examinadora Jose Eugenio e Hugo Repolho com as ricas contribuições.

Aos professores da UERJ, Francisco Jose Soeiro e Manoel Antonio da Fonseca que me concederam a carta de recomendação para a minha entrada no mestrado.

À Petrobras, especialmente a Abdias F. Ramos e Antônio Felipe Harboe que possibilitou o meu desenvolvimento e me proporcionaram realizar o mestrado.

A Milton Marchesi pela imensa ajuda na discussão de pontos técnicos e pela leitura atenciosa do texto.

Aos meus queridos amigos me apoiaram, acompanharam todas as etapas da dissertação.

À PUC-Rio, que me proporcionou esta etapa de desenvolvimento, representada pelo corpo docente altamente qualificado do Departamento de Engenharia Industrial.

Enfim agradeço de coração a todos que diretamente ou indiretamente contribuíram para a finalização da dissertação.

Muito Obrigado 


\section{Resumo}

Araujo, Lucio Cerqueira de Amorim; Hamacher, Silvio; Soares de Mello, João Carlos Correia Baptista. Avaliação da Eficiência Operacional de Terminais Aquaviários de Carga Líquida. Rio de Janeiro, 2015. 88p. Dissertação de Mestrado - Departamento de Engenharia Industrial, Pontifícia Universidade Católica do Rio de Janeiro.

Esta dissertação pretende avaliar a eficiência dos terminais aquaviários de uma empresa do setor petroquímico que movimenta petróleo e derivados no Brasil, utilizando uma técnica não paramétrica denominada Data Envelopment Analysis (DEA). Os terminais são o principal elo na cadeia logística de abastecimento de combustíveis. Devido à produção dos campos do pré-sal, ao aumento da capacidade de refino e à limitação da empresa em investimento e ao crescente aumento do mercado, a busca pela excelência no desempenho se torna um fator estratégico para a empresa. Neste trabalho são identificados quais terminais podem ser usados como benchmark, que características estão relacionadas nesta classificação. As variáveis utilizadas para determinar a eficiência foram a quantidade movimentada, o número de operadores, o número de berços e o tempo de operação. Os resultados sugerem que a eficiência dos terminais difere por regiões do país. O estudo também identifica a contribuição dos insumos e produtos para os níveis de eficiência, assim como as causas da ineficiência. Sendo assim, as conclusões alcançadas buscam auxiliar os tomadores de decisão nas suas ações estratégicas.

\section{Palavras-chave}

Cadeia de Suprimentos da Indústria de Petróleo; Portos; Desempenho; Data Envelopment Analysis. 


\section{Abstract}

Araujo, Lucio Cerqueira de Amorim; Hamacher, Silvio ( Adivisor); Soares de Mello, João Carlos Correia Baptista (Co-Adivisor). Assessment the Efficiency of Waterway Liquid Bulk Cargo Terminals. Rio de Janeiro, 2015. 88p. MSc. Dissertation- Departamento de Engenharia Industrial, Pontifícia Universidade Católica do Rio de Janeiro.

This work aims to evaluate the efficiency of liquid bulk cargo terminals of a petrochemical company that moves oil and oil products in Brazil, using a nonparametric technique called DEA (Data Envelopment Analysis). The terminals are the main link in the petroleum supply logistics chain. Due to production of pre-salt fields, increased refining capacity and the company's limited investment and the increasing market, the pursuit of excellence in performance becomes a strategic factor for the company. This work identified which terminals can be used as benchmark, which characteristics are related in this classification. The variables used to determine the efficiency were: the total cargo throughput, the number of workers, the number of berths and time of operation. The results suggest that the terminals efficiency differs by regions. The study also identifies the contribution of inputs and products for efficiency levels, as well as the causes of inefficiency. Therefore, the conclusions reached are to assist decision makers in their strategic actions.

\section{Keywords}

Supply Chain in Petroleum Industry; Ports; Performance; Data Envelopment Analysis 


\section{Sumário}

1 . Introdução

2. DEA - Revisão Bibliográfica 14

2.1. Conceitos Básicos de DEA 14

2.1.1. Conceito de DMU 14

2.1.2. Conceito de eficácia e eficiência 15

$\begin{array}{ll}\text { 2.1.3. Conceito de produtividade } & 15\end{array}$

2.1.4. Eficiência Total e Relativa 15

2.1.5. DEA e Regressão Linear 16

2.2. Modelos de Formulação de DEA Clássicos 19

2.2.1. CCR - Orientado ao Insumo 19

2.2.2. CCR - Orientado ao Produto 25

2.2.3. BCC - Orientado ao Insumo 27

2.2.4. BCC - Orientado ao Produto 29

2.3. Etapas da Modelagem DEA 31

2.3.1. Escolha das DMUs 31

2.3.2. Escolha das variáveis 31

2.3.3. Escolha do modelo 32

2.4. Objetivos 19

2.5. Características Importantes 18

2.6. Desvantagens do DEA 18

2.7. Modelos de Formulação Avançados 33

2.7.1. Métodos que consideram informação prévia 33

2.7.2. Métodos que não consideram informação prévia 33

2.8. Aplicações e Estatísticas 39

3. Portos e Terminais 41

3.1. Definição de Porto e Terminal 41

3.2. Importância dos Portos 42

3.3. Importância dos Terminais de Combustível 43

3.4. O Estudo de Desempenho dos Portos e Terminais 44

4. Abordagens de DEA no setor Portuário. 47

4.1. Modelagem com DEA aplicada a Portos e Terminais 47

4.1.1. Modelo de Formulação $\quad 47$ 
4.1.2. Seleção dos Insumos e Produtos 48

4.1.3. Seleção dos Portos 50

4.2. Artigos em DEA com portos 51

4.2.1. Aplicações de DEA a portos do Brasil 54

5. Aplicação de um Modelo de Análise de Envoltória 65

5.1. Cenário do Modelo 68

5.1.1. Descrição dos terminais analisados 68

5.2. Modelo e Fatores de produção utilizados 65

5.2.1. Seleção dos terminais 65

5.2.2. Escolha das Variáveis 65

$\begin{array}{ll}\text { 5.2.3. Definição do Modelo } & 67\end{array}$

6. Apresentação e Análise dos Resultados Encontrados 71

6.1. Classificação quanto à eficiência 71

§ $\quad$ 6.2. Pesos atribuídos aos fatores de cada terminal 72

6.3. Principais benchmarks de cada terminal 76

$\begin{array}{ll}\text { 6.4. Metas a serem alcançadas } & 76\end{array}$

$\begin{array}{ll}\text { 6.5. Considerações } & 78\end{array}$

7. Conclusão $\quad 80$

8. Referências bibliográficas 82 


\section{Lista de figuras}

$\begin{array}{ll}\text { Figura 1- Fronteira DEA e Regressão Linear } & 17\end{array}$

Figura 2- Folga e Alvo 22

Figura 3- CCR- Insumo para únicos fatores $\quad 25$

Figura 4- Convexidade do BCC- Insumo 27

Figura 5- Fronteira Invertida 39

$\begin{array}{ll}\text { Figura 6- Metas para o tempo de operação } & 77\end{array}$

Figura 7- Metas para o número de operadores $\quad 77$

Figura 8- Metas para o número de berços $\quad 78$

\section{Lista de tabelas}

$\begin{array}{lr}\text { Tabela 1- Diferença entre DEA e SFA } & 18\end{array}$

Tabela 2- Matriz de eficiência cruzada 36

$\begin{array}{ll}\text { Tabela 3- Insumos e produtos dos terminais } & 67\end{array}$

Tabela 4- Classificação por Eficiência dos Terminais $\quad 72$

Tabela 5- Peso das Variáveis 73

Tabela 6- Importância Relativa das Variáveis $\quad 75$

Tabela 7- Benchmarks 76 


\section{1. \\ Introdução}

Em um mundo globalizado, com mercados competitivos e economias afetadas por crises internacionais, a demanda por ganho de eficiência vem se tornando um dos pontos-chave para as organizações.

Dentre os elementos analisados para se conseguir esta eficiência estão os portos e os terminais. Segundo Dutra et al. (2015), a economia global exige mais eficiência dos portos devido à:

- intensificação crescente da globalização,

- relocação da produção para locais de menor custo de insumo,

- adoção de economias de mercado pelos países,

- redução do custo de transporte,

- maior agilidade no processo de frete,

- mudanças políticas e gerências na administração dos portos e

- incorporação de novas tecnologias.

Nesta busca pelo desempenho, ferramentas que possam avaliar, monitorar e identificar a eficiência dos portos e terminais vem atraindo interesse da comunidade acadêmica e das empresas que são pressionadas por melhores práticas.

Muito embora a importância dos portos para economia de um país seja um consenso na literatura, conforme será demonstrado neste estudo, há uma escassez de artigos sobre a avaliação do desempenho de terminais de carga líquida, principalmente envolvendo os países da América do Sul.

De acordo com o plano estratégico para 2030 da empresa a ser estudada, a produção de petróleo deve aumentar de 2,1 milhões barris por dia (bpd) em 2014, para em média 2,8 milhões bpd em 2020. A capacidade de refino deve aumentar com a entrada de duas novas refinarias, com uma demanda de derivados crescente a uma taxa de $1,6 \%$ ao ano, chegando a 2,9 milhões de bpd em 2020.

Este aumento na movimentação exigirá terminais com elevado desempenho, o que depende das suas características, nomeadamente das infraestruturas e equipamentos, da sua governança e da forma como se integram nas cadeias logísticas. 
Esta dissertação se propõe a descrever um modelo matemático que, através da técnica de Análise de Envoltória de Dados - DEA, possa avaliar a eficiência operacional de terminais aquaviários de carga combustíveis líquidos.

Além de identificar os terminais que se mostram mais eficientes em suas operações, pretende-se:

- identificar quais terminais podem ser usados como benchmark para os terminais que ainda apresentam ineficiências,

- analisar a razão da ineficiência dos terminais e

-determinar metas para os terminais ineficientes para alcançarem a eficiência.

Para isso foram analisados 16 terminais aquaviários que operam combustíveis derivados de petróleo em relação aos seus insumos: número de mão de obra, número de berços e tempo de operação de navio e seus produtos, volume de produto movimentado.

Após a revisão da literatura encontrada e entrevistas com especialistas da área de logística da empresa e coordenadores de operação dos terminais, foram selecionados os fatores a serem analisados. As informações foram obtidas pelo banco de dados da empresa, e por questionário a cada coordenador de cada terminal.

Utilizaram-se dados e informações quantitativas dos terminais, referentes ao ano de 2014, para fazer uma análise através de um modelo matemático que classifique os terminais em relação a sua eficiência na utilização dos fatores selecionados.

A modelagem matemática através da Análise de Envoltória de Dados (DEA) foi utilizada como ferramenta para medir a eficiência destes terminais, pois permite a análise da eficiência de unidades organizacionais com a presença de vários insumos e produtos. O modelo DEA permite estabelecer quais terminais podem ser considerados benchmark e as metas para os que foram considerados ineficientes.

Finalmente, os resultados obtidos foram confrontados com especialistas da empresa, a fim de se obterem as possíveis causas das ineficiências encontradas.

Esta pesquisa é classificada quanto aos fins como aplicada, pois é motivada pela necessidade de resolver problemas de eficiência operacional dos terminais. Tem, portanto, finalidade prática, motivada pela necessidade de se estudar quais fatores produtivos são melhores aproveitados nesses terminais devido à demanda crescente de combustíveis e de movimentação de produtos. 
Quanto aos meios de investigação, é classificada como: bibliográfica, pois é feito um estudo sistematizado desenvolvido com base em material publicado em livros, revistas, jornais e redes eletrônicas, visando fornecer instrumental analítico à pesquisa; documental, pois utiliza dados de operação dos terminais a serem estudados e estudo de caso, pois compara e classifica os terminais aquaviários de uma empresa de petróleo.

Quanto à natureza, é quantitativa, pois usa dados e informações quantitativas dos terminais para que se faça uma análise através de um modelo matemático a fim de estabelecer uma classificação desses terminais.

Além da introdução, este trabalho compreende outros sete capítulos. O capitulo II apresenta um resumo sobre a metodologia DEA e suas aplicações. Serão discutidas as definições básicas da técnica, modelagem características e limitações.

Nos capítulos III e IV, definem-se portos e terminais, ressaltando sua importância e os principais estudos sobre desempenho de portos. Destacam-se as categorias em que os estudos de portos se dividem e as técnicas utilizadas nesses estudos. Faz-se ainda uma revisão bibliográfica do estudo de desempenho de portos utilizando DEA.

Os capítulos V e VI mostram uma aplicação do modelo caracterizando cada terminal escolhido, apresentam-se os dados escolhidos e justifica-se sua seleção. Por fim, é feita uma análise dos resultados encontrados.

O capitulo VII descreve as conclusões do estudo e propõe estudos futuros.

Finalmente, temos no capítulo VIII as referências. 


\section{2.}

\section{DEA - Revisão Teórica.}

Neste capitulo, será feita uma revisão de Análise de Envoltória de Dados (DEA), com seus principais conceitos, formulação de modelos clássicos e avançados, etapas para uma modelagem em DEA, objetivos a serem alcançados, vantagens e desvantagens desta técnica.

\section{1.}

\section{Conceitos Básicos de DEA}

O DEA é uma técnica de programação matemática não paramétrica desenvolvida por Charnes et al. (1978), utilizada para medir a eficiência relativa de unidades organizacionais, com a presença de vários inputs e outputs. Charnes et al. (1994) definem DEA como uma técnica para a mensuração da eficiência relativa de unidades similares que executam as mesmas funções, denominadas Unidades de Tomada de Decisão (DMU - Decision Making Units)

Segundo Lins e Angulo-Meza (2000), a abordagem analítica aplicada às medidas de eficiência originou-se com Pareto-Koopmans e Debreu em 1951. Ainda de acordo com Lins e Angulo-Meza (2000), Farrell (1957) deu continuidade aos estudos de Pareto (1909), Koopmans (1951) e Debreu (1951), ao incluir um componente denominado eficiência alocativa capaz de refletir a habilidade dos produtores em selecionar o vetor insumo-produto eficiente considerando os respectivos preços. A dificuldade para se medir esses preços de forma acurada, levaram Charnes et al. (1978) aos trabalhos com DEA que enfatizassem a medida de eficiência técnica.

\subsection{1.}

\section{Conceito de DMU}

Charnes et al. (1978) definem as Unidades Tomadoras de Decisão (DMUs) como um conjunto de unidades a serem avaliadas que possuem múltiplos insumos e produtos em comum.

Originalmente o termo DMU era empregado para enfatizar o interesse em avaliar "unidades organizacionais" que não visassem somente resultados 
financeiros, isto é o peso atribuído a cada insumo ou produto não seria função do lucro, custo de produção ou qualquer outra medida relacionada. Aplicar-se-ia a instituições como hospitais, escolas, departamentos públicos etc.

\subsection{2.}

\section{Conceito de Eficácia e Eficiência}

Segundo Soares de Melllo et al. (2005) eficácia é a capacidade de uma DMU alcançar sua meta de produção, não considerando a quantidade de recursos usados para a produção.

A eficiência está relacionada com a relação entre o que foi produzido dado aos recursos disponíveis e ao que poderia ter sido produzido com os mesmos recursos.

\subsection{3.}

\section{Conceito de Produtividade}

Segundo Coelli et al. (2005), produtividade de uma empresa ou unidade organizacional é a relação entre as saídas produzidas (produto) e os recursos necessários para produzir estas saídas (insumo).

\section{Produtividade $=$ Produto $/$ Insumo}

A escolha de decisões, de forma que os recursos sejam melhor aproveitados, leva a classificar uma empresa como mais produtiva. Essas decisões podem ser: o uso de uma tecnologia mais avançada, a contratação de mão de obra mais qualificada ou melhores técnicas gerenciais, entre outras, (Soares de Mello et al., 2005)

\subsection{4.}

\section{Eficiência Total e Relativa}

Cooper et al. (2011) definem que a eficiência total de uma DMU somente é alcançada se nenhum de seus insumos ou produtos puderem ser melhor utilizados ou produzidos sem que se piore algum outro insumo ou produto. Pode se dizer que uma DMU é relativamente eficiente se seu indicador da medida de eficiência for, no mínimo, maior que as demais unidades, usando-se os mesmos pesos.

A eficiência relativa de uma organização é avaliada calculando-se a razão entre a produtividade observada dessa DMU e a maior produtividade observada no conjunto das DMUs sob análise. Em DEA, essa eficiência relativa visa 
construir fronteiras de eficiência, que separam as DMUs observadas em duas categorias: as eficientes, cujos planos de operação executados pertencem à fronteira de eficiência, e as ineficientes, cujos planos não estão na fronteira.

A eficiência relativa pode estar associada à produtividade de uma empresa por um valor escalar, entretanto é restrita ao conjunto de empresas que está sendo avaliado. Isto significa que os valores de produtividade para cada unidade do conjunto sofrem influência com a retirada de uma ou mais unidades. Assim, o que está sendo calculado é a eficiência relativa de cada unidade pertencente à amostra.

\subsection{5.}

\section{DEA e Regressão Linear}

Conforme se pode observar na Figura 1, a diferença entre os métodos paramétricos, cujo objetivo é otimizar um plano de regressão simples, e o método DEA está na formação da fronteira de eficiência através da otimização individual de cada uma das observações em relação às demais, (Charnes et al., 1994). No método DEA existe uma flexibilidade em que valores dos pesos diferem de unidade para unidade. Essa fronteira de eficiência é definida, segundo o conceito de Pareto-Koopmans (Charnes et al., 1985), pelo nível máximo de produção para um dado nível de insumo. A distância de cada DMU à fronteira é que estabelece a medida de eficiência, ou seja, a distância relativa para as melhores práticas.

Segundo Cook et al. (2014), o DEA se diferencia da Regressão Linear das seguintes maneiras:

- em DEA é preciso assegurar que as variáveis selecionadas reflitam adequadamente, na maior medida possível, o processo estudado e

- para a regressão, o tamanho da amostra é um problema crítico, já que estima o comportamento médio de um conjunto. Já em DEA, como ferramenta de benchmarking, foca no desempenho individual de cada DMU, sendo o tamanho da amostra irrelevante. 


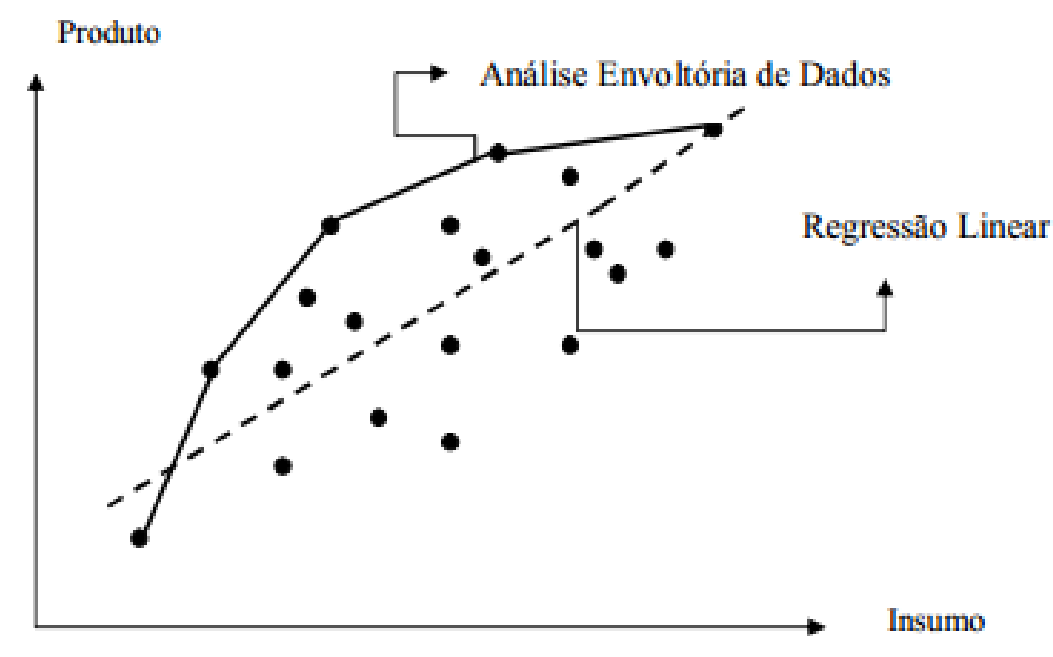

Figura 1- Fronteira DEA e Regressão Linear

Fonte: Charnes et al. (1994) adaptado

Uma vantagem importante do DEA sobre os demais métodos, é que não requer a especificação de uma função de produção ou de custo.

Segundo Farrell (1957), a eficiência de uma firma podia ser avaliada por dois componentes:

- eficiência técnica, que reflete a habilidade da firma em obter o máximo de produção, dado um conjunto de insumos e

- eficiência alocativa, que reflete a habilidade da firma em utilizar os insumos em proporções ótimas, dados seus preços relativos.

Essas duas medidas seriam combinadas para se obter uma medida de eficiência econômica total.

\subsection{6}

\section{DEA e Fronteira Estocástica}

A fronteira estocástica é um método paramétrico econométrico no qual a fronteira de eficiência é estimada estatisticamente, baseada na análise de regressão, a partir da máxima quantidade de produto possível para uma determinada combinação de insumos. As funções de produção são especificadas por parâmetros e requerem uma distribuição de erro. Com isso, podem-se confundir erros com ineficiência (Acosta et al., 2011).

A Tabela 1 resume as principais diferenças entre DEA e SFA: 


\begin{tabular}{l|l}
\hline DEA- Data Envelopment Analysis & SFA- Stochastic Frontier Analysis \\
\hline método não paramétrico & método paramétrico \\
método determinístico & método estocástico \\
não permite a hipótese da estatística & permite a hipótese estatística \\
não realiza suposições na distribuição & realiza suposições na distribuição do \\
do termo da ineficiência & termo da ineficiência \\
não inclui o erro como termo & inclui um termo composto de erro \\
não existe uma função especifica & exige uma função especifica \\
sensível na relação entre o nº de & pode confundir ineficiência caso o \\
variáveis e DMUs & modelo tenha sido mal definido \\
método de programação linear & método econométrico \\
\hline
\end{tabular}

Tabela 1- Diferença entre DEA e SFA

Fonte: González e Trujillo (2009)

\section{2.}

\section{Características Importantes}

Algumas características importantes da técnica DEA são (Charnes et al., 1994):

- opera com múltiplos insumos e produtos,

- não necessita estipular a forma funcional,

- gera uma classificação de desempenho para cada unidade em relação às demais,

- diferencia as unidades eficientes das ineficientes,

- calcula o nível de ineficiência das unidades ineficientes e

- detecta ineficiências especificas não possíveis em outras técnicas.

\section{3.}

\section{Desvantagens do DEA}

A técnica DEA é uma das mais utilizadas para medir a eficiência. Entretanto, como as DMUs são livres para encontrar a eficiência, ou seja, são analisadas por um ponto de vista otimista, a técnica apresenta as seguintes desvantagens: (Angulo-Meza e Lins, 2002).

- "problema" dos pesos nulos, folgas não nulas e empates,

- falta de discriminação das DMUs eficientes, que ocorre quando há um número restrito de DMUs em relação ao $\mathrm{n}^{\circ}$ de variáveis analisadas, 
- pesos desproporcionais com a real importância destes para o sistema e

- soluções ótimas múltiplas para DMUs eficientes.

\section{4.}

\section{Objetivos:}

O objetivo principal de DEA é comparar as DMUs selecionadas para análise, que apresentam uma homogeneidade nas atividades que realizam, diferenciando-se nas quantidades de insumos e produtos. (Soares de Mello et al., 2005). Dentre outros objetivos destacam-se:

- identificar as DMUs eficientes,

- medir e localizar as ineficientes,

- identificar o benchmark,

- estabelecer os alvos para as ineficientes,

- subsidiar estratégias de produção e

- auxiliar nas tomadas de decisão.

\section{5.}

\section{Modelos de Formulação de DEA Clássicos}

O modelo DEA desenvolvido por Charnes et al. (1978) ficou conhecido por CCR, que provém das iniciais dos autores (Charles, Cooper e Rhodes). Os modelos CCR supõem retornos constantes de escala, nos quais qualquer variação nos insumos corresponde a uma variação proporcional nos produtos.

Mais tarde, em 1984, Banker, Charnes e Cooper propuseram um modelo alternativo que ficou conhecido como BCC, em que os retornos de escala são variáveis. No modelo BCC, as DMUs que trabalham com baixos valores de insumo têm retorno crescente de escala e as que trabalham com altos valores de insumos têm retorno de escala decrescente.

Os modelos podem ser orientados aos insumos ou aos produtos. No primeiro caso, a eficiência é atingida com a redução dos recursos. No segundo, se maximizam as saídas, porém mantêm inalteradas as entradas.

\subsection{1.}

\section{CCR - Orientado ao Insumo}

O modelo CCR orientado ao Insumo é apresentado nas equações (1), (2), (3) e (4): 
Função Objetivo:

$$
\operatorname{Max} \frac{\left(\sum_{j \in J} u_{j} \cdot y_{j o}\right)}{\left(\sum_{i \in I} v_{i} \cdot x_{i o}\right)} \quad \text { eficiência relativa }
$$

Sujeito a :

$$
\begin{array}{ll}
\frac{\left(\sum_{j \in J} u_{j} \cdot y_{j k}\right)}{\left(\sum_{i \in I} v_{i} \cdot x_{i k}\right)} \leq 1, \forall k \in D & \text { eficiência máxima. } \\
u_{j} \geq 0, \forall i \in I & \text { cond. de não negatividade } \\
v_{i} \geq 0, \forall j \in J &
\end{array}
$$

$$
\begin{array}{cl}
\text { em que: } \mathrm{K}: & \text { conjunto das DMUs }(1, \ldots, \mathrm{s}) \\
\mathrm{I}: & \text { conjunto dos insumos } \mathrm{i}(1, \ldots, \mathrm{n}) \\
\mathrm{J}: & \text { conjunto dos produtos } \mathrm{j}(1, \ldots, \mathrm{m}) \\
\mathrm{x}_{\mathrm{ik}}: & \text { insumo i para DMU } \mathrm{k} \\
\mathrm{y}_{\mathrm{jk}}: & \text { produto j para DMU } \mathrm{k} \\
\mathrm{x}_{\mathrm{i} 0}: & \text { insumo i para DMU observada }(>0) \\
\mathrm{y}_{\mathrm{jo}}: & \text { produto j para DMU observada }(>0) \\
\mathrm{v}_{\mathrm{i}}: & \text { peso dado ao insumo } \mathrm{i} \\
\mathrm{u}_{\mathrm{j}}: & \text { peso dado ao produto } \mathrm{j}
\end{array}
$$

A função objetivo (1) calcula a eficiência da DMU observada através da maximização da razão entre as somas ponderadas dos produtos pelos insumos.

A restrição (2) garante que a eficiência de qualquer DMU do conjunto em análise não seja maior que 1 quando utilizados os pesos ótimos da DMU observada.

As restrições (3) e (4) garantem que os pesos não sejam negativos.

O problema apresentado pelas equações (1), (2), (3) e (4) deve ser resolvido para calcular a eficiência de cada DMU selecionada.

As variáveis do problema são os pesos de cada insumo $\left(v_{i}\right)$ e produto $\left(u_{j}\right)$ e a solução encontra os pesos que mais favorecem a DMU observada a atingir a eficiência.

Transformando de uma programação fracionária em uma programação linear, temos as equações (5), (6), (7), (8) e (9):

Função Objetivo:

$$
\operatorname{Maxh}_{\mathrm{o}}=\sum_{j \in J} u_{j} \cdot y_{j o}
$$


Sujeito a:

$$
\begin{aligned}
& \sum_{i \in I} v_{i} \cdot x_{i o}=1 \\
& \sum_{j \in J} u_{j} \cdot y_{j k}-\sum_{i \in I} v_{i} \cdot x_{i k} \leq 0 \\
& u_{j} \geq 0, \forall j \in J \\
& v_{i} \geq 0, \forall i \in I
\end{aligned}
$$

A modelagem apresentada no sistema de equações (5), (6), (7), (8) e (9) representa o modelo dos multiplicadores orientado ao insumo, sendo o conjunto de pesos denominado de multiplicadores. Já o seu dual é conhecido como modelo envelope, conforme o sistema de equações (10), (11), (12) e (13):

$\operatorname{Min} \theta$

sujeito a:

$$
\begin{aligned}
& \theta \cdot x_{i o}-\sum_{k} x_{i k} \lambda_{k} \geq 0, \forall i \\
& -y_{j o}+\sum_{k} y_{j k} \lambda_{k} \geq 0, \forall j \\
& \lambda_{k} \geq 0, \quad \forall \mathrm{k}
\end{aligned}
$$

em que:

$\theta$ : $\quad$ é o valor que deve ser multiplicado por todos os insumos de forma a obter valores que coloquem a DMU na fronteira eficiente

$$
\begin{array}{ll}
\lambda_{\mathrm{k}}: & \text { é a contribuição da DMU k na formação da } D M U_{\circ} \\
\mathrm{x}_{\mathrm{ik}}: & \text { insumo i para DMU k } \\
\mathrm{y}_{\mathrm{jk}}: & \text { produto j para DMU k } \\
\mathrm{x}_{\mathrm{io}}: & \text { insumo i para DMU observada }(>0) \\
\mathrm{y}_{\mathrm{j} 0}: & \text { produto j para DMU observada }(>0)
\end{array}
$$

Para se construir o modelo dual, é associada uma variável dual $\theta$ à restrição (6) e $\lambda_{k}$ que são as variáveis duais associadas à restrição (7). 
A restrição (11) garante que a redução em cada um dos inputs não ultrapasse a fronteira definida pelas DMUs eficientes. Já a restrição (12) garante que a redução nos inputs não altere o nível dos outputs da DMU.

A determinação das DMUs que serão utilizadas como benchmark é obtida pelo cálculo dos $\lambda$ 's. Um valor de $\lambda$ elevado indica uma maior relevância da DMU correspondente como referência para a DMU ineficiente. Por sua vez, um $\lambda$ nulo indica que sua respectiva DMU não é benchmark para a DMU em análise.

A explicação para a relação dos valores dos $\lambda$ 's e a determinação dos benchmarks vêm da teoria da programação linear. Os $\lambda$ 's são os preços- sombra relacionados à restrição do modelo dos multiplicadores (primal) que limitam a eficiência de cada unidade não ser maior que um. Onde a restrição é ativa, o preço-sombra vai ser positivo e onde a restrição é não ativa, o preço- sombra vai ser nulo. Na solução do modelo primal uma restrição ativa, significa que a DMU correspondente tem uma eficiência igual a 1 e vai existir um preço- sombra positivo. Logo, preços-sombra positivos no primal ou $\lambda$ 's positivos no dual correspondem à identificação de uma referência para a DMU ineficiente.

\subsubsection{1.}

\section{Folga e Alvo}

Na Figura 2 é observada a representação de um modelo CCR em que se tem um único produto para todas as DMUs, resultado da utilização de dois insumos, onde são feitos os comentários:

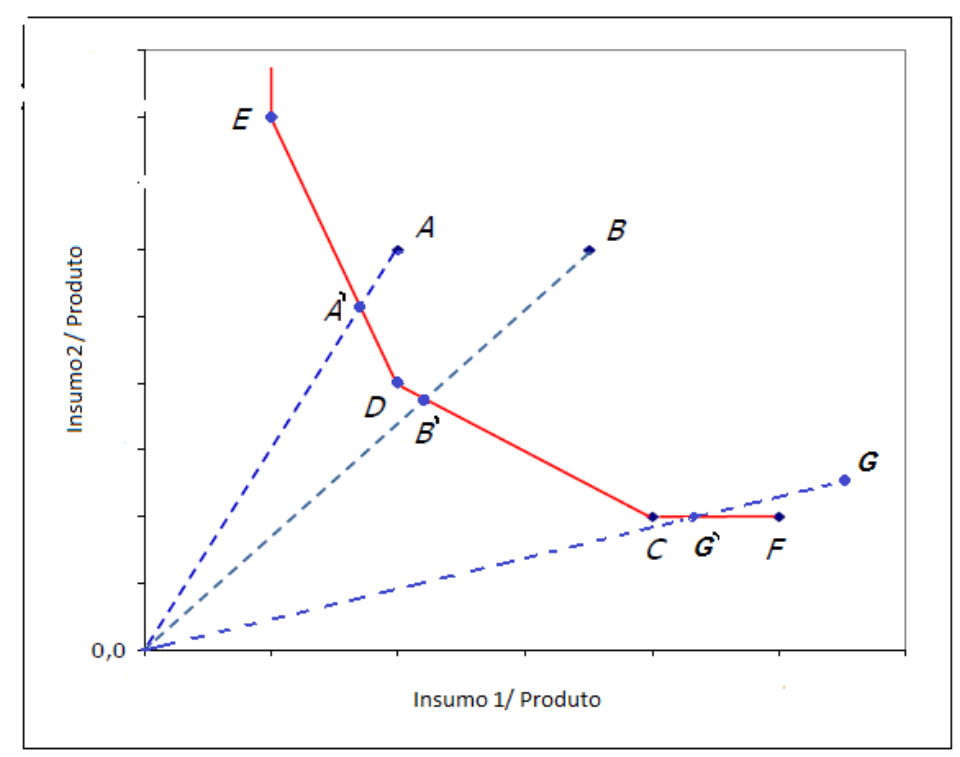

Figura 2- Folga e Alvo

Fonte: Charnes et al. (1991) adaptado 
A curva EDCF, chamada de fronteira de eficiência, determina as DMUs eficientes, logo, as DMUs A, B e G são ineficientes.

O ponto A' é a meta de A para alcançar a eficiência, isto é, o alvo de $A$, que é a combinação linear da DMU E com D. Isto é, D e E são benchmarks de $A$.

$O$ cálculo da eficiência de $A$ é dado por $\left(\mathrm{Eff}_{\mathrm{A}}=\mathrm{OA}^{\prime} / O A\right)$

Como a reta CF é paralela ao eixo horizontal, é possível reduzir o Insumo 1 mantendo-se constante o insumo 2 e mesmo assim permanecer na região viável de produção. Essa quantidade de insumo que é possível ser reduzida é denominada de folga. As DMUs eficientes que possuem folga são denominadas de fracamente eficiente.

A DMU G é dita envolvida inapropriadamente, pois seu alvo G' esta em uma extensão da fronteira de eficiência, logo é fracamente eficiente, ou seja, C será benchmark de $\mathrm{G}$

Para o modelo DEA CCR orientado ao insumo, a folga nula ocorre quando as restrições do sistema de equações (11) e (12) são nulas, para outputs e inputs, respectivamente, com valores ótimos de $\theta$ e $\lambda_{k}$.

$$
\begin{aligned}
& \theta \cdot x_{i o}-\sum_{k} x_{i k} \lambda_{k}=0 \\
& \sum_{k} y_{j k} \lambda_{k}-y_{j o}=0
\end{aligned}
$$

\subsubsection{2. \\ Modelo Aditivo}

Posteriormente ao modelo CCR, Charnes et al. (1981) impuseram que os pesos aplicados às variáveis deveriam ter um limite mínimo maior que zero, através de um número não arquimediano $(\varepsilon)$, e consideraram a presença de folgas ao insumo $\left(\mathrm{s}_{\mathrm{i}}\right)$ e ao produto $\left(\mathrm{s}_{\mathrm{j}}\right)$ orientadas. O objetivo era tornar as DMUs fracamente eficientes em ineficientes.

A função objetivo no modelo-envelope é apresentada por Charnes et al. (1981) em (14).

$$
\operatorname{Min} \theta-\varepsilon\left(\sum_{i=1}^{n} s_{i}^{-}-\sum_{j=1}^{m} s_{j}^{+}\right)
$$


Em um segundo momento Charnes et al. (1985) propuseram uma nova função objetivo considerando somente estas folgas. O modelo-envelope aditivo pode ser visto no sistema de equações (15), (16), (17) e (18):

$$
\operatorname{Min} \sum_{i=1}^{n} s_{i}^{-}-\sum_{j=1}^{m} s_{j}^{+}
$$

sujeito a:

$$
\begin{array}{ll}
\sum_{\mathrm{k}=1}^{\mathrm{s}} \lambda_{k .} x_{i k}+s_{i}^{-}=x_{i o} & \mathrm{i}=1, \ldots, \mathrm{n} \\
\sum_{k=1}^{s} \lambda_{k .} y_{j k}-s_{j}^{+}=y_{j o} & \mathrm{j}=1, \ldots, \mathrm{m}, \\
\lambda_{\mathrm{k}}, \mathrm{s}_{\mathrm{j}}^{+}, \mathrm{s}_{\mathrm{i}}^{-} \geq 0 & \mathrm{k}=1, \ldots, \mathrm{s} \\
\text { em que: } &
\end{array}
$$

$\begin{array}{ll}\mathrm{s}_{\mathrm{i}}^{-} & \text {folga de insumo } \\ \mathrm{s}_{\mathrm{j}}{ }^{+} & \text {folga de produto } \\ \lambda_{\mathrm{k}}: & \text { é a contribuição da DMU k na formação da DMUo } \\ \mathrm{x}_{\mathrm{ik}}: & \text { insumo i para DMU k } \\ \mathrm{y}_{\mathrm{jk}}: & \text { produto j para DMU k } \\ \mathrm{x}_{\mathrm{i} 0}: & \text { insumo i para DMU observada }(>0) \\ \mathrm{y}_{\mathrm{j} 0}: & \text { produto j para DMU observada }(>0)\end{array}$

A Figura 3 apresenta uma representação gráfica de um modelo CCR com um produto $(X)$ e um insumo $(Y)$, em que o valor de $\theta$ para a DMU 3 pode ser observado. 


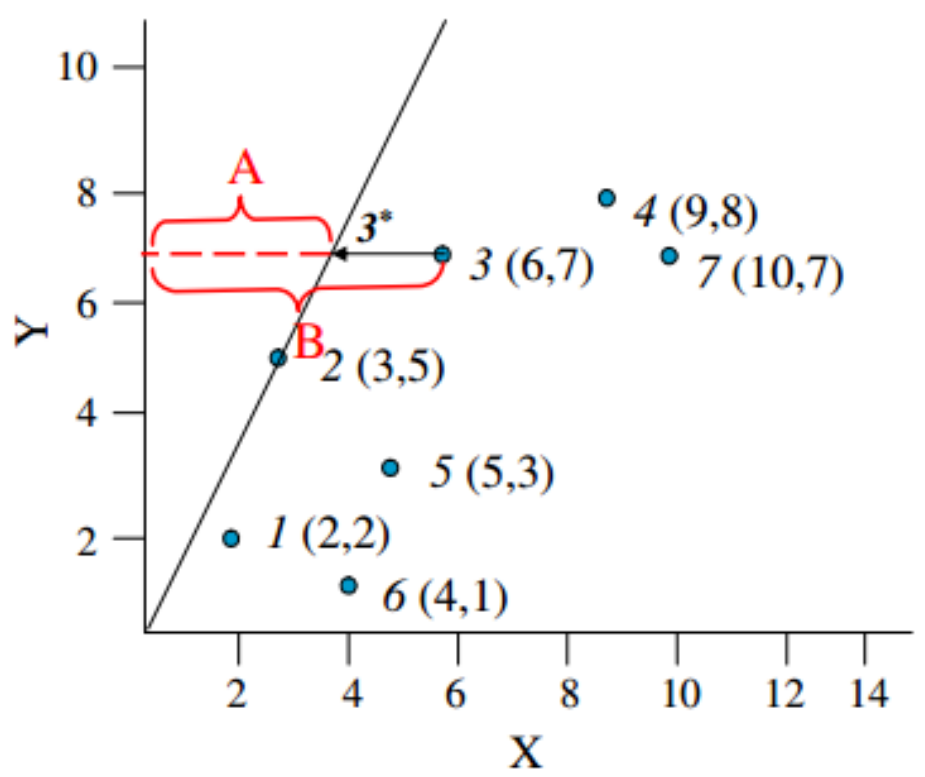

Figura 3- CCR- Insumo para únicos fatores

Fonte: Cook (2009)

A eficiência da DMU 3 é dada pela razão das distâncias $A$ e $B$, ou seja, $4,2 / 7$ que resulta em $\theta_{3}=0,70$.

Coelli (1998) provou que o modelo aditivo não é eficaz na identificação de benchmark para as DMUs ineficientes, pois sempre identifica a DMU mais extrema.

\subsection{2.}

\section{CCR - Orientado ao Produto}

Neste modelo mantêm-se constantes os recursos e há um incremento dos produtos. Com esta orientação $\theta$ assume valores maiores que 1, que correspondem ao inverso da eficiência.

O modelo-envelope é apresentado no sistema de equações (19), (20), (21) e (22):

$$
\operatorname{Max} \theta
$$

sujeito a:

$$
\begin{aligned}
& x_{i o}-\sum_{k} x_{i k} \lambda_{k} \geq 0, \forall i \\
& -\theta y_{j o}+\sum_{k} y_{j k} \lambda_{k} \geq 0, \forall j
\end{aligned}
$$

$\lambda_{k} \geq 0, \quad \forall k$

em que: 
$\theta$ : $\quad$ é o valor que deve ser multiplicado por todos os produtos de forma a obter valores que coloquem a DMU na fronteira eficiente.

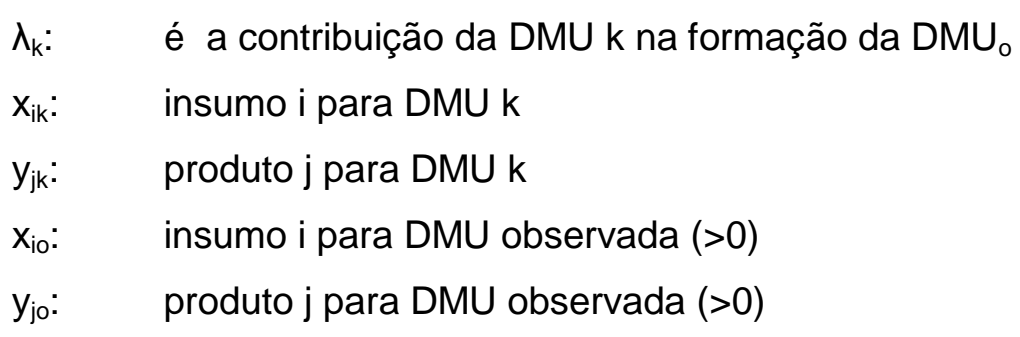

A restrição (20) garante que o aumento em cada um dos produtos não ultrapasse a fronteira definida pelas DMUs eficientes. Já a restrição (21) garante que o aumento dos produtos não altere o nível dos insumos da DMU.

O sistema de equações (23), (24), (25), (26) e (27) apresenta o modelo dos multiplicadores:

Função Objetivo:

Sujeito a:

$$
\begin{aligned}
& \qquad \operatorname{Min}_{i \in I} v_{i} \cdot x_{i o} \\
& \sum_{j \in J} u_{j} \cdot y_{j o}=1 \\
& \sum_{j \in J} u_{j} \cdot y_{j k}-\sum_{i \in I} v_{i} \cdot x_{i k} \leq 0 \\
& v_{i} \geq 0, \forall i \in I \\
& u_{j} \geq 0, \forall j \in J \\
& \text { em que: } \\
& \mathrm{x}_{\mathrm{ik}:} \quad \text { insumo i para DMU k } \\
& \mathrm{y}_{\mathrm{jk}}: \quad \text { produto j para DMU k } \\
& \mathrm{x}_{\mathrm{io}}: \quad \text { insumo i para DMU observada }(>0) \\
& \mathrm{y}_{\mathrm{jo}}: \quad \quad \text { produto j para DMU observada }(>0)
\end{aligned}
$$

A restrição (24) garante que o somatório dos produtos da DMU observada não seja maior que 1 .

A restrição (25) garante que a eficiência da DMU sob análise não seja maior que 1 quando utilizados os pesos ótimos da DMU observada. 
No modelo CCR, os resultados obtidos para a eficiência serão os mesmos quando orientados para insumo ou produto, no entanto, os valores dos $\lambda$ 's serão diferentes.

\subsection{3.}

\section{BCC - Orientado ao Insumo}

No modelo BCC a proporcionalidade entre os insumos e produtos é substituída por uma convexidade. Para isso, é feita uma restrição adicional que requer que o somatório dos $\lambda$ seja igual a 1, ou seja, a soma das contribuições k's DMU na formação do alvo da $\mathrm{DMU}_{0}$ é 1.( Banker et al., 1984)

Ao obrigar que a fronteira seja convexa, o modelo permite que DMUs que operam com baixos valores de insumos tenham retornos crescentes de escala $e$ as que operam com altos valores tenham retorno decrescente de escalas.

A Figura 4 apresenta uma representação gráfica para o modelo BCC e CCR com orientação ao insumo para um modelo de um único insumo e um único produto. $\mathrm{O}$ eixo horizontal representa o insumo e o eixo vertical representa o produto.

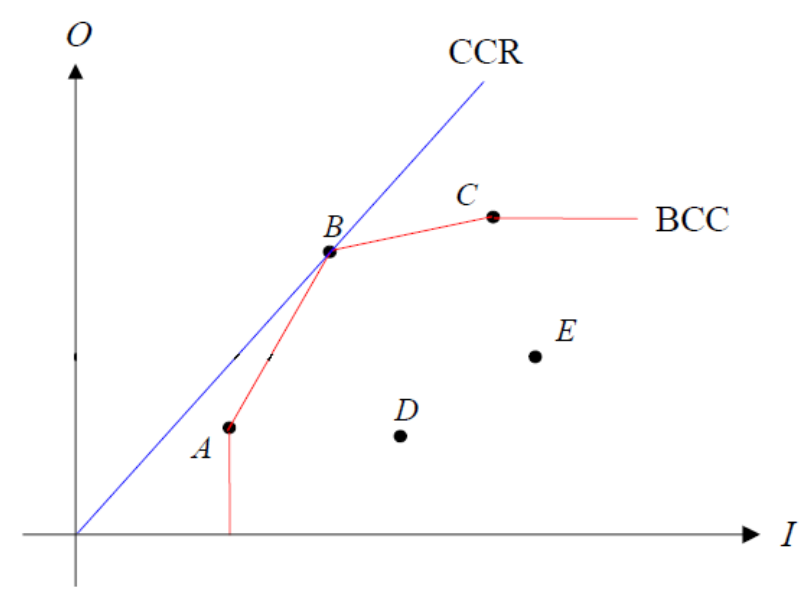

Figura 4 - Convexidade do BCC- Insumo Fonte: Coelli et al. (2005).

O modelo-envelope com orientação aos insumos é apresentado nos sistemas de equações (28), (29), (30), (31) e (32).

$\operatorname{Min} \theta$

sujeito a: 


$$
\begin{aligned}
& \theta \cdot x_{i o}-\sum_{k} x_{i k} \lambda_{k} \geq 0, \forall i \\
& -y_{j o}+\sum_{k} y_{j k} \lambda_{k} \geq 0, \forall j \\
& \sum_{k} \lambda_{k}=1
\end{aligned}
$$

$\lambda_{k} \geq 0, \forall \mathrm{k}$

em que:

$\theta$ representa quanto os insumos das DMUs devem ser multiplicados, mantendo-se constantes os produtos, para a $\mathrm{DMU}_{0}$ atingir a fronteira eficiente.

$\lambda_{k} \quad$ é a contribuição da DMU k na formação da DMUo

$\mathrm{X}_{\mathrm{ik}} \quad$ são os insumos da DMU $k$

$\mathrm{y}_{\mathrm{jk}}$ : $\quad$ produto j para DMU $\mathrm{k}$

$\mathrm{x}_{\mathrm{io}}$ : $\quad$ insumo i para DMU observado $(>0)$

$\mathrm{y}_{\mathrm{jo}}: \quad$ produto j para DMU observado $(>0)$

A restrição (29) garante que a redução em cada um dos inputs não ultrapasse a fronteira definida pelas DMUs eficientes. Já a restrição (30) garante que a redução nos inputs não altere o nível dos outputs da DMU.

A restrição (31) garante que as DMUs que operam com baixos valores de insumo tenham retorno crescente de escala e as que operam com altos valores de insumo tenham retorno decrescente de escala.

O seu dual, o modelo dos multiplicadores, é encontrado associando a variável dual u* à restrição (31), conforme podem ser vistos nas equações (33) a (37):

$$
\operatorname{Max} \sum_{j \in J} u_{j} \cdot y_{j o}-u_{*}
$$

Sujeito a:

$$
\begin{aligned}
& \sum_{j \in J} v_{i} x_{i o}=1 \\
& \sum_{j \in J} u_{j} y_{j k}-\sum_{i \in I} v_{i} x_{i k}-u_{*} \leq 0, \forall k \\
& v_{i} \geq 0, \forall i \in I \\
& u_{j} \geq 0, \forall j \in J
\end{aligned}
$$


em que: K: $\quad$ conjunto das DMUs $(1, \ldots, \mathrm{s})$

I: $\quad$ conjunto dos insumos $\mathrm{i}(1, \ldots, \mathrm{n})$

$\mathrm{J}$ : $\quad$ conjunto dos produtos $\mathrm{j}(1, \ldots, \mathrm{m})$

$\mathrm{x}_{\mathrm{ik}}$ : insumo i para DMU $\mathrm{k}$

$\mathrm{y}_{\mathrm{jk}}$ : produto j para DMU $\mathrm{k}$

$\mathrm{x}_{\mathrm{i} 0}$ : $\quad$ insumo i para DMU observado $(>0)$

$\mathrm{y}_{\mathrm{j} 0}: \quad$ produto j para DMU observado $(>0)$

$\mathrm{v}_{\mathrm{i}}$ : $\quad$ peso dado ao insumo $\mathrm{i}$

$\mathrm{u}_{\mathrm{j}}$ : $\quad$ peso dado ao produto $\mathrm{j}$

$u_{*}$ fator de escala, variável dual associada a condição $\sum_{k} \lambda_{k}=1$

\subsection{4.}

\section{BCC - Orientado ao Produto}

Nos sistemas de equações (38) a (42) apresenta-se o modelo dos multiplicadores e o seu dual, o modelo-envelope, apresenta-se no sistema de equações (43) a (47), ambos com orientação ao produto:

- Modelo dos multiplicadores

Função Objetivo:

$$
\operatorname{Min} \sum_{i \in I} v_{i} \cdot x_{i o}+v_{*}
$$

Sujeito a:

$\sum_{j \in J} u_{j} y_{j o}=1$

$\sum_{j \in J} u_{j} y_{j k}-\sum_{i \in I} v_{i} x_{i k}-v_{*} \leq 0, \forall k$

$v_{i} \geq 0, \forall i \in I$

$u_{j} \geq 0, \forall j \in J$

em que: K: $\quad$ conjunto das DMUs $(1, \ldots, \mathrm{s})$

I: $\quad$ conjunto dos insumos $i(1, \ldots, n)$

$\mathrm{J}$ : conjunto dos produtos $\mathrm{j}(1, \ldots, \mathrm{s})$

$\mathrm{x}_{\mathrm{ik}}$ : insumo i para DMU $\mathrm{k}$ 


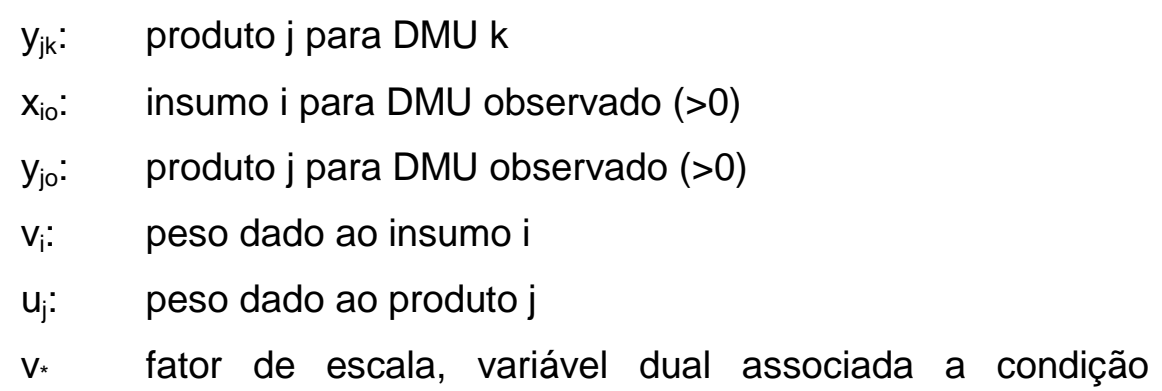
$\sum_{k} \lambda_{k}=1$

Segundo Soares de Mello et al. (2005), os fatores de escala no modelo orientado aos insumos, quando positivos, indicam retornos crescentes de escala; quando negativos, indicam retornos decrescentes de escala e caso sejam nulos, a situação é de retornos constantes de escala. Já no modelo orientado aos produtos, quando positivos, indicam retornos decrescentes de escala; quando negativos, indicam retornos crescentes de escala e caso sejam nulos, a situação é de retornos constantes de escala.

- Modelo-envelope:

Função-objetivo

$$
\operatorname{Max} \theta
$$

sujeito a:

$$
\begin{aligned}
& x_{i o}-\sum_{k} x_{i k} \lambda_{k} \geq 0, \forall i \\
& -\theta y_{j o}+\sum_{k} y_{j k} \lambda_{k} \geq 0, \forall j \\
& \sum_{k} \lambda_{k}=1
\end{aligned}
$$

$\lambda_{k} \geq 0, \forall \mathrm{k}$

em que:

$\theta$ representa quanto os produtos das DMUs devem ser multiplicados, mantendo-se constantes os insumos, para a $\mathrm{DMU}_{0}$ atingir a fronteira eficiente.
$\lambda_{k}$ é a contribuição da DMU k na formação da DMUo
$\mathrm{x}_{\mathrm{ik}} \quad$ são os insumos da DMU $\mathrm{k}$
$\mathrm{y}_{\mathrm{jk}}: \quad$ produto j para DMU $\mathrm{k}$
$\mathrm{x}_{\mathrm{io}}$ : $\quad$ insumo i para DMU observado $(>0)$
$\mathrm{y}_{\mathrm{jo}}: \quad$ produto j para DMU observado $(>0)$ 


\section{6.}

\section{Etapas da Modelagem DEA}

Antes de realizar uma análise pelo método DEA, é necessário definir as DMUs a serem comparadas e classificadas, as variáveis de insumo e de produto e o modelo de formulação.

\subsection{1.}

\section{Escolha das DMUs}

A grande controvérsia em DEA é que se procuram diferenças entre indivíduos de um grupo homogêneo, que devem ter as seguintes características, (Dyson et al., 2001):

- devem realizar a mesma atividade com o mesmo objetivo,

- os fatores de insumo e produto devem ser os mesmos para todas as

DMUs, diferenciando-se por intensidade ou magnitude e

- evitar grandes variações de ambiente, nas quais as DMUs se encontram.

Além disso, o período de tempo a ser considerado deve corresponder a ciclos normais. Grandes ou pequenos períodos podem mascarar o resultado da análise.

\subsection{2.}

\section{Escolha das Variáveis}

$\mathrm{Na}$ escolha das variáveis, é preciso um entendimento claro do processo a ser estudado, assegurando que as variáveis escolhidas são aquelas que melhor refletem este processo (Cook et al., 2014).

Estas variáveis podem não ser consideradas como insumos e produtos de acordo com a definição de produção clássica, isto é, não representam uma fronteira de produção, mas sim uma fronteira que indica as melhores práticas. De acordo com Golany e Roll (1989), o DEA fornece uma avaliação da eficiência relativa com uma presunção mínima da relação entre insumos e recursos.

É preciso considerar que o método sempre irá minimizar os insumos e maximizar os produtos, e que pequenas quantidades de insumos e grandes quantidades de produtos representam um melhor desempenho, (Cook et al., 2014). 
É preciso levar em consideração o objetivo de benchmarking, o qual se quer alcançar, pois dependendo do processo, a mesma variável pode ser considerada como insumo em um caso e como produto em outro.

Outro fator importante em DEA são as variáveis indesejáveis de insumos ou de produtos. Estas variáveis são aquelas em que o aumento de um insumo provoca uma redução do produto ou produtos que devem ter valores mínimos. Como solução, os valores de alguns fatores podem ser invertidos antes da análise.

Alguns pontos podem ser considerados como críticos na escolha das variáveis: (Dyson et al., 2001).

- contribuem com os objetivos da eficiência a ser estudada,

- não estão inclusas em outros fatores,

- quando existem variáveis que são razões de mais de um fator,

- os dados a serem analisados estão disponíveis e

- é necessário que os fatores possuam um valor numérico.

A fim de se evitar a falta de discrepância de eficiência entre as DMUs, alguns autores sugerem uma relação entre o número de DMUs e a soma dos fatores (insumos e produtos). Para Golany e Roll (1989), o ideal é que seja de no mínimo o dobro de DMUs em relação ao total de variáveis. Já Banker et al. (1989) sugerem três vezes mais. Estas regras podem ser ignoradas quando se utilizam alguns modelos específicos.

Devido à restrição do número de variáveis em relação ao número de DMUs, nem sempre é possível utilizar todas as variáveis encontradas. Existem métodos de seleção dos insumos e produtos. Esta seleção pode ser feita por um método estatístico (Lins e Moreira, 1999) ou com técnicas de multicritério (Soares de Mello et al., 2002; Senra et al., 2007).

\subsection{3.}

\section{Escolha do Modelo}

O propósito da medida de desempenho influencia diretamente a orientação do modelo. Uma vez, determinado este propósito, é preciso estabelecer qual orientação mais se adequa ao objetivo: redução dos insumos, aumento dos produtos ou, em um caso especial, ambos os fatores.

Segundo Cook et al. (2014) se o objetivo for determinar as melhores práticas, a orientação não terá influência. Porém, a classificação das unidades será diferente. 
Se um insumo no modelo CCR com orientação ao produto ou um produto no modelo CCR com orientação ao insumo tem o mesmo valor para todas as DMUs então seria mais adequado o modelo BCC.

Quando se utiliza o modelo BCC com variáveis em unidades percentuais, o resultado do modelo conserva estas percentagens. Porem, quando utilizamos 0 modelo CCR esta situação pode não ser preservada.

\section{7. \\ Modelos de Formulação Avançados}

Segundo Adler et al. (2002), os modelos clássicos de DEA classificam as DMUs em dois grupos: os eficientes e os ineficientes. Uma vez essas DMUs classificadas como eficientes, elas não podem ser mais comparadas entre si, (Lofti et al., 2013). Devido à necessidade de se ranquear todas as DMUs, foram desenvolvidas soluções que complementassem a análise dos modelos clássicos. Angulo-Meza e Lins (2002) classificaram essas soluções para as desvantagens apresentadas em DEA em dois grupos:

- métodos que consideram informações prévias de um especialista e

- métodos que não consideram informações previas.

\subsection{1.}

\section{Métodos que consideram informação prévia:}

Neste grupo, é necessário o conhecimento de um especialista que conheça todo o processo e decida a importância de cada fator de produção na análise com DEA. Entre os principais métodos destacam-se:

- restrição de pesos,

- estrutura de preferências e

- análise do valor da eficiência.

\subsection{2.}

\section{Métodos que não consideram informação prévia}

Nos métodos anteriores, os julgamentos ou as considerações do especialista podem estar erradas, serem tendenciosas ou ainda pode haver uma falta de consenso entre os especialistas, o que pode gerar um engano na conclusão. 
Devido a isso, alguns estudos preferem não considerar informação prévia de um especialista. Dentre os principais métodos destacam se:

- avaliação cruzada,

- aproximação por MOLP e

- fronteira invertida.

\subsubsection{1.}

\section{Avaliação Cruzada:}

Neste modelo que foi apresentado por Sexton et al. (1986) e desenvolvido por Doyle e Green (1994), é feita uma avaliação conjunta (peer-evaluation), ao invés de se fazer uma avaliação que melhor beneficie a DMU avaliada. Enquanto no DEA clássico cada DMU é avaliada segundo seu próprio ponto de vista, na avaliação cruzada ela também é avaliada segundo os pontos de vista das outras DMUs. Chama-se eficiência cruzada à medida do ponto de vista de todas as DMU's (Leta et al., 2005).

O processo de avaliação é feito em duas etapas: primeiro determina-se a eficiência segundo o modelo clássico escolhido e segundo, determina-se os pesos ótimos de cada DMU.

Para escolher entre os vários possíveis valores para os pesos ótimos de cada DMU, arbitra-se que estes, quando aplicados a outras DMUs, devem minimizar a sua eficiência (formulação agressiva) ou maximizá-la (benevolente).

Os cálculos dos pesos na formulação agressiva são dados pelo sistema de equações (48) a (52), desenvolvido por Sexton et al. (1986):

$$
\begin{gathered}
\operatorname{Min} \sum_{\mathbf{j}}\left(\mathbf{u}_{\mathbf{j k}} \sum_{\mathbf{s} \neq \mathbf{k}} \mathbf{y}_{\mathbf{j s}}\right) \\
-\sum_{\mathbf{i}}\left(\mathbf{v}_{\mathbf{i k}} \sum_{\mathbf{s} \neq \mathbf{k}} \mathbf{x}_{\mathbf{i s}}\right)
\end{gathered}
$$

sujeito a:

$$
\begin{aligned}
& \sum_{j} v_{i k} x_{i k}=1 \\
& \sum_{i} u_{j k} y_{j k}-E_{k k} \sum_{j} v_{i k} x_{i k}=0 \\
& \sum_{\mathrm{j}} \mathrm{u}_{\mathrm{jk}} \mathrm{y}_{\mathrm{js}}-\sum_{\mathrm{i}} \mathrm{v}_{\mathrm{ik}} \mathrm{x}_{\mathrm{is}} \leq 0, \forall \mathrm{s} \neq \mathrm{k}
\end{aligned}
$$


$u_{\mathrm{jk}} v_{\mathrm{ik}} \geq 0$

em que: $x_{i s}$ : insumo i para DMU $s$

$\mathrm{y}_{\mathrm{js}}: \quad$ produto j para DMU $\mathrm{s}$

$\mathrm{x}_{\mathrm{ik}}$ : $\quad$ insumo i para DMU $\mathrm{k}$

$\mathrm{y}_{\mathrm{jk}}$ : $\quad$ produto j para DMU $\mathrm{k}$

$\mathrm{V}_{\mathrm{ik}}$ : $\quad$ peso dado ao insumo i da DMU $\mathrm{k}$

$\mathrm{u}_{\mathrm{jk}}$ : $\quad$ peso dado ao produto j da DMU j

A eficiência da DMU s usando os pesos da DMU k é dada em (53):

$$
\mathbf{E}_{\mathrm{ks}}=\frac{\sum_{\mathrm{j}} \mathbf{u}_{\mathrm{jk}} \mathbf{y}_{\mathbf{j s}}}{\sum_{\mathrm{i}} \mathbf{v}_{\mathbf{i k}} \mathbf{x}_{\mathrm{is}}}
$$

Doyle e Green (1994) sugeriram o sistema de equações (54):

$$
\operatorname{Min} \sum_{\mathbf{j}}\left(\mathbf{u}_{\mathbf{j k}} \cdot \sum_{\mathbf{s} \neq \mathbf{k}} \mathbf{y}_{\mathbf{j} s}\right)
$$

sujeito a:

$$
\begin{aligned}
& \sum_{j}\left(v_{i k} \sum_{s \neq k} x_{i k}\right)=1 \\
& \sum_{i} u_{j k} y_{j k}-E_{k k} \sum_{j} v_{i k} x_{i k}=0
\end{aligned}
$$$$
\sum_{j} u_{j k} y_{j s}-\sum_{i} v_{i k} x_{i s} \leq 0, \forall s \neq k
$$

$u_{\mathrm{jk}} v_{\mathrm{ik}} \geq 0$

Segundo Angulo-Meza e Lins (2002), os dois modelos anteriores derivam em resultados similares, por isso geralmente se usam mais as últimas equações (54) a (58).

Após estabelecidos os pesos e encontradas as eficiências cruzadas, constrói-se a matriz de eficiência cruzada(Tabela 2). Através da média dos valores das eficiências da coluna k, é possível avaliar a eficiência da DMU k.

\begin{tabular}{cccccc}
\hline & 1 & 2 & 3 & $\ldots$ & $\mathrm{n}$ \\
\hline 1 & $\mathrm{E}_{11}$ & $\mathrm{E}_{12}$ & $\mathrm{E}_{13}$ & $\ldots$ & $\mathrm{E}_{1 \mathrm{n}}$ \\
2 & $\mathrm{E}_{21}$ & $\mathrm{E}_{22}$ & $\mathrm{E}_{23}$ & $\ldots$ & $\mathrm{E}_{2 \mathrm{n}}$ \\
3 & $\mathrm{E}_{31}$ & $\mathrm{E}_{32}$ & $\mathrm{E}_{33}$ & $\ldots$ & $\mathrm{E}_{3 \mathrm{n}}$ \\
$\ldots$ & $\ldots$ & $\ldots$ & $\ldots$ & $\ldots$ & $\ldots$ \\
$\mathrm{n}$ & $\mathrm{E}_{\mathrm{n} 1}$ & $\mathrm{E}_{\mathrm{n} 2}$ & $\mathrm{E}_{\mathrm{n} 3}$ & $\ldots$ & $\mathrm{E}_{\mathrm{nn}}$ \\
\hline & $\mathrm{e}_{1}$ & $\mathrm{e}_{2}$ & $\mathrm{e}_{3}$ & $\ldots$ & $\mathrm{em}$ \\
\hline
\end{tabular}


Tabela 2- Matriz de eficiência cruzada

Fonte: Angulo-Meza e Lins (2002).

$E_{k k}=\left\{E_{11}, E_{22}, E_{33}, \ldots, E_{n n}\right\}$
$E_{k s}=\left\{E_{12}, E_{13}, \ldots, E_{1 n}, E_{21}, \ldots, E_{n-1}\right\}$

em que:

$$
e_{k}=\frac{1}{n} \sum_{\forall s} E_{s k}
$$

Segundo Talluri e Sarkis (1997), quando a relação entre a eficiência padrão $\left(E_{k k}\right)$ e a eficiência média cruzada é muito alta, isto indica que a DMU obteve um resultado de eficiência através de pesos inapropriados. Este resultado é conhecido como falso positivo e pode ser encontrado pelas equações (60) e (61):

$$
\mathbf{M}_{\mathbf{k}}=\frac{\left(\mathbf{E}_{\mathbf{k k}}-\mathbf{e}_{\mathbf{k}}^{\prime}\right)}{\mathbf{e}_{\mathbf{k}}^{\prime}}
$$

em que:

$$
e_{k}^{\prime}=\frac{1}{n-1} \sum_{s \neq k} E_{s k}
$$

\subsubsection{2. \\ Aproximação por Multiobjetivo}

O modelo multiobjetivo MCDEA foi desenvolvido por Li e Reeves (1999) e utiliza a a Progamação Linear Multiobjetivo (PLMO) para resolver os problemas de discriminação das DMUs e promover uma melhor distribuição dos multiplicadores para as variáveis.

Para isso, foram adicionadas duas novas funções-objetivo ao DEA clássico: uma que minimiza o desvio máximo ("equidade") e outra que minimiza a soma dos desvios ("benevolência generalizada"). As funções-objetivo são independentes em relação às demais, não havendo ordem de prioridade entre os critérios de eficiência.

A formulação se dá em função da folga $d_{0}$, que é o complemento da eficiência $\left(d_{0}=1-h_{0}\right)$, através de uma minimização da ineficiência restringida à soma ponderada dos produtos ser menor ou igual à soma ponderada dos 
insumos de cada DMU. O sistema de equações (62) a (68) apresenta a formulação para o MCDEA:

Função Objetivo: $\quad$ Min $d_{0}$

$\operatorname{Min} \operatorname{Max} d_{k}$

$$
\operatorname{Min} \sum_{k=1}^{n} d_{k}
$$

Sujeito a:

$$
\begin{aligned}
& \sum_{j \in J} v_{i} x_{i o}=1 \\
& \sum_{j \in J} u_{j} y_{j k}-\sum_{i \in I} v_{i} x_{i k}+d_{k}=0, \forall k \\
& v_{i} \geq 0, \forall i \in I \\
& u_{j} \geq 0, \forall j \in J
\end{aligned}
$$

onde: $d_{0}$ : folga da DMU em observação

$d_{k}$ : folga da DMU $k$

$\mathrm{x}_{\mathrm{ik}}$ : $\quad$ insumo i para DMU $\mathrm{k}$

$\mathrm{y}_{\mathrm{jk}}: \quad$ produto j para DMU $\mathrm{k}$

$\mathrm{x}_{\mathrm{io}}$ : $\quad$ insumo i para DMU observado $(>0)$

$\mathrm{y}_{\mathrm{jo}}$ : $\quad$ produto j para DMU observado $(>0)$

$v_{\mathrm{j}}$ : $\quad$ peso dado ao produto $\mathrm{j}$

$\mathrm{u}_{\mathrm{i}}$ : $\quad$ peso dado ao insumo $\mathrm{i}$

\subsubsection{3.}

\section{Fronteira Invertida (Dupla Envoltória)}

Baseado no conceito de ranking das DMUs ineficientes, encontrado em Adler et al. (2002). O conceito de fronteira invertida foi introduzido por Yamada et al. (1994) e desenvolvido por Entani et al. (2002) adotado por e Angulo-Meza et al. (2003), Lins, de Lyra Novaes e Legey (2005); Leta et al. (2005); Entani e Tanaka (2006).

Para Ângulo-Meza et al.(2003), a fronteira invertida é uma avaliação pessimista, formada pelas unidades organizacionais com as piores práticas gerenciais. Já Lins, de Lyra Novaes e Legey (2005) definem a fronteira invertida como as melhores práticas sob a ótica oposta. 
Pode-se observar que o cálculo da fronteira ineficiente é feito por uma substituição dos insumos pelos produtos no sistema de equações do modelo de DEA clássico, apresentado em (69) a (73):

$$
\operatorname{Max} \sum_{j \in J} u_{i} \cdot x_{i o}-u_{*}
$$

Sujeito a:

$$
\begin{aligned}
& \sum_{j \in J} v_{j} y_{j o}=1 \\
& \sum_{j \in J} u_{i} y_{i k}-\sum_{i \in I} v_{j} x_{j k}-u_{*}=0, \forall k \\
& v_{j} \geq 0, \forall i \in I \\
& u_{i} \geq 0, \forall j \in J
\end{aligned}
$$

em que: $\mathrm{K}: \quad$ conjunto das $\operatorname{DMUs}(1, \ldots, \mathrm{s})$

I: $\quad$ conjunto dos insumos $\mathrm{i}(1, \ldots, \mathrm{n})$

$\mathrm{J}: \quad$ conjunto dos produtos $\mathrm{j}(1, \ldots, \mathrm{s})$

$\mathrm{x}_{\mathrm{ik}}$ : insumo i para DMU $\mathrm{k}$

$\mathrm{y}_{\mathrm{jk}}: \quad$ produto j para DMU $\mathrm{k}$

$\mathrm{x}_{\mathrm{io}}$ : $\quad$ insumo i para DMU observado $(>0)$

$\mathrm{y}_{\mathrm{jo}}$ : $\quad$ produto j para DMU observado $(>0)$

$\mathrm{v}_{\mathrm{j}}$ : $\quad$ peso dado ao produto $\mathrm{j}$

$\mathrm{u}_{\mathrm{i}}$ : $\quad$ peso dado ao insumo $\mathrm{i}$

u* fator de escala, variável dual associada a condição $\sum_{k} \lambda_{k}=1$

A ordenação das DMUs se realiza através do cálculo da eficiência composta, fórmula (74), que consiste na média aritmética entre a eficiência em relação à fronteira clássica e o complemento da ineficiência em relação à fronteira invertida. Depois, é feita uma normalização, através da divisão de todos os valores pelo maior índice calculado, (Soares de Mello et al., 2008a)

$$
E f f_{\text {composta }}=\frac{E f f_{\text {padrão }}+\left(1-E f f_{\text {invertida }}\right)}{2}
$$

Segundo Maciel et al. (2014), a fronteira invertida não permite a especialização das DMUs. Esta especialização ocorre, porque nos modelos clássicos as DMUs atribuem pesos nulos às variáveis que não têm um bom desempenho, ou seja, algumas DMUs têm seus pesos não nulos somente em 
algumas variáveis. A fronteira invertida contorna esse efeito destacando também variáveis nas quais as DMUs não têm bom desempenho.

A fronteira invertida também evita distorções provocadas pelas DMUs falsamente eficientes. Isto ocorre, porque no modelo BCC as unidades que têm o menor valor de um dos insumos ou maior valor de um dos produtos serão considerados eficientes. (Soares de Mello et al., 2008b)

Para Soares de Mello et al. (2008a), a diferença entre o método de fronteira invertida e os demais métodos de DEA é que na composição do score de eficiência os demais métodos consideram somente os dados mais otimistas, ao contrário do método de fronteira invertida que considera os dados por uma ótica pessimista.

Na Figura 5, são apresentadas as duas fronteiras, a clássica e a invertida, para o caso de DEA BCC.

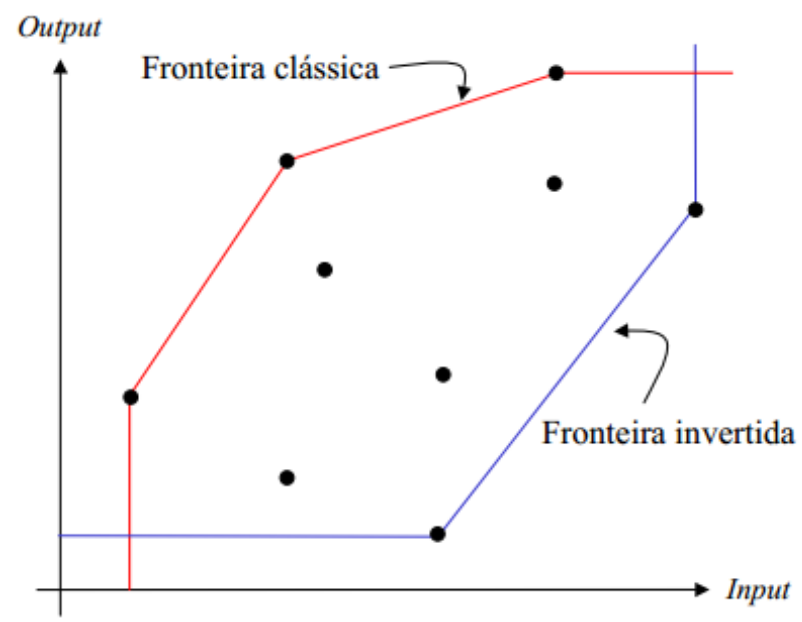

Figura 5-Fronteira Invertida

Fonte: Soares de Mello et al. (2005)

\section{8.}

\section{Aplicações e Estatísticas:}

Desde sua criação por Charnes et al. (1978), o método de DEA evoluiu para as mais diversas áreas desde educação, na qual foi criado, até a previsão de sucessos e insucessos empresariais através de índices baseados em DEA.

Emrouznejad et al. (2008) e Liu et al. (2013a, e 2013b) estudaram através de artigos publicados em jornais científicos quais áreas de indústrias os autores sob DEA mais se direcionavam. De acordo com estes autores, estas áreas são: bancos, saúde, agricultura, transporte e educação. Estas áreas correspondem a mais de $40 \%$ dos artigos que cobrem estudos de caso. Segundo Liu (2013b), atualmente as áreas que têm um aumento mais acelerado são: energia e meio ambiente e financeira. 
Liu et al. (2013b) descrevem como principais fatores para a concentração de artigos em DEA nestas áreas: a necessidade de mensurar o desempenho, a acessibilidade aos dados e o suporte dado por alguns jornais.

Na pesquisa de Liu et al. (2013a), os artigos aplicados a ou que continham estudos de casos correspondiam a mais de $60 \%$ dos artigos encontrados na Web of Science. Os artigos mais antigos, anteriores a 1999, se concentravam em desenvolvimento de novos modelos de DEA.

O "boom" dos artigos sob DEA se deu a partir dos anos 2000, devido ao aparecimento de programas computacionais (software) de DEA como DEAP, DEASolver, DEA Frontier, e SIAD que facilitaram os cálculos e análises. Até 1990, o número de autores era na ordem de 200, sendo que em 2009 o número já passava dos 4000 .

Entre os Jornais que mais foram encontrados artigos de DEA destacam-se: European Journal of Operation Research, Journal of Productivity Analysis, Omega International Journal of Management Science. Destacam se ainda para os que contêm artigos de metodologia: Journal of Operation Research Society e Applied Economics e os que contêm artigos com estudo de caso: Management Science e Journal of Productivity Analysis. 


\section{3. \\ Portos e Terminais}

Neste capitulo pretende-se definir e diferenciar o conceito de Porto e Terminal, destacando a importância de um porto para o desenvolvimento de um país e, dentro deste contexto, a importância dos terminais de combustível e as principais categorias de estudos e técnicas utilizadas na avaliação do desempenho de portos.

\section{1.}

\section{Definição de Porto e Terminal}

O porto é definido como a instalação construída e aparelhada para atender às necessidades da navegação, da movimentação de passageiros ou da movimentação e armazenagem de mercadorias, concedido ou explorado pela União, cujo tráfego e operações portuárias estejam sob a jurisdição de uma autoridade portuária, (Decreto 6620/08 - Políticas e Diretrizes para Portos e Terminais Portuários).

Entretanto, para alguns autores, a definição de porto vai além dos serviços aos navios e às cargas, abrangendo o elo logístico que inclui as atividades das empresas que participam do comércio marítimo, tendo a função econômica de atender às demandas dos produtores das mercadorias nas exportações e dos consumidores nas importações e de contribuir com menores custos totais de transporte e distribuição.

Os objetivos dos portos são: atingir o máximo de tráfego, garantir o fluxo na rede intermodal de transporte de mercadorias e fortalecer a economia de sua região de influência agregando valor a esta. (Pizzolato et al., 2010; Rodrigues, 2011; Bichou e Gray, 2005)

Em termos gerais, o porto agrega valor à região de influência por:

- gerar empregos diretos e indiretos,

- arrecadar impostos,

- exportar o excedente de produção da região e

- ser um catalisador econômico e 
Rodriguez (2011) define o Porto com uma visão utópica, como aquele que maximiza a economia do país nas áreas político-econômicas, urbanistas, sociais e do meio ambiente, além de ser autônomo financeiramente sobre sua área de gestão. Numa visão mais realista, os portos visam atender aos navios com alto grau de mecanização, associado à elevada produtividade com baixos níveis de acidentes e total integração com seus clientes e autoridades aduaneiras.

O crescimento do tamanho dos navios e da sua velocidade, assim como a especialização dos mesmos na busca de ganho de escala, obrigaram os portos a se desenvolverem. Os grandes investimentos no setor armador, com o consequente crescimento do tempo de amortização dos navios, fizeram com que a redução do tempo de estadia dos navios no porto passasse a ser fundamental. A mecanização da manipulação das mercadorias melhorou a rapidez das operações, reduzindo, em consequência, a duração das escalas.

O terminal é uma instalação não integrante do patrimônio do porto público, construída por empresa privada ou entidade pública para a movimentação e armazenagem de carga própria ou de terceiros, destinada ou proveniente de transporte aquaviário, (Decreto 6620/08).

Os terminais portuários, que se caracterizam por movimentarem cargas da mesma natureza, podem ser: graneis líquidos, graneis sólidos, carga geral, congelados, resfriados, veículos e contêineres, surgiram devido à necessidade dos navios se especializarem (navios graneleiros, roll-on-of, full-contêineres e mistos) para obterem melhores rendimentos a custos menores.

Os terminais são um importante elo na cadeia logística de abastecimento de uma empresa do setor petrolífero. Das plataformas ou campos terrestres de produção, o petróleo é transportado por navios ou por oleodutos, para os terminais e de lá é exportado ou segue até as refinarias. Após o refino, os derivados são novamente escoados por dutos aos terminais para serem exportados ou serem entregues às companhias distribuidoras, que abastecem o mercado nacional.

\section{2.}

\section{Importância dos Portos}

Segundo Tovar e Ferreira (2006), o desenvolvimento de um país está relacionado diretamente com a eficiência dos portos. A redução dos custos operacionais e a melhora do nível de serviços portuários refletem positivamente na economia. 
Dados da Organização Mundial do Comércio (OMC) mostram que o volume do comércio cresceu entre 1990 e 2004 quase três vezes mais que Produto Interno Bruto (PIB) das nações signatárias. Isto denota que houve transferência da produção para outros países em esforço de reestruturação produtiva (Galvão et al., 2013).

Visto isso, o papel dos portos marítimos ganha destaque, uma vez que são a principal via para o comércio exterior e estão entre os principais atores na determinação da competitividade para os produtos de um país.

O transporte marítimo é a espinha dorsal do comércio e o motor principal da globalização. Cerca de $80 \%$ do comércio mundial em volume e mais de $70 \%$ em valor são transportados por mar e são manipulados pelos portos em todo o mundo. Esses valores são ainda maiores no caso da maioria dos países em desenvolvimento (United Nations Conference on Trade and Development UNCTAD, 2012).

\section{3.}

\section{Importância dos Terminais de Combustível}

O comércio de petróleo e derivados detém cerca de $29,8 \%$ do volume do comércio marítimo, em que se destaca a crescente demanda do Brasil por derivados de petróleo (UNCTAD, 2014).

A crise hidrográfica, que o país vem enfrentando desde 2013, reflete-se no consumo de petróleo e derivados. Com o nível das represas abaixo do volume morto e a maior participação das usinas termoelétricas na produção de energia, o Brasil ultrapassou a Arábia Saudita e chegou ao sétimo lugar no ranking dos maiores consumidores de petróleo em 2014.

Além de estar entre os maiores consumidores mundiais de petróleo e derivados, segundo dados da Associação Internacional de Energia (AIE) de 2015, o país é o maior produtor da América Latina e Caribe de petróleo, considerando somente os países não membros da Organization of the Petroleum Exporting Countries (OPEC).

Em uma análise dos dados estatísticos divulgados pela Agencia Nacional de Petróleo (ANP), em 2014, o Brasil importou 20\% de todo o volume consumido de petróleo e derivados e exportou $17 \%$ de toda produção de petróleo e derivados, (ANP, 2015). Segundo o Ministério do Desenvolvimento Indústria e Comercio (MDIC), os gastos do país com importação de combustíveis são um dos principais fatores que contribuíram para o déficit da balança comercial em 
2014. O valor atinge $15 \%$ de todo o montante importado pelo país, contra $11 \%$ de todo o montante que foi exportado em 2014 (MDIC, 2015).

Segundos dados da Agência Nacional de Transportes Aquaviários ANTAQ (2014), em torno de $80 \%$ das cargas transportadas por cabotagem são cargas liquidas. Quando se analisa somente o transporte de petróleo e seus derivados, este percentual é de $77 \%$ do total dessas cargas transportadas. Já para as movimentações de petróleo e derivados no Brasil, o transporte aquaviário pode ser considerado como principal meio de transporte entre os polos costeiros.

Contribuem para essa movimentação o fato de que a uma distância máxima de $500 \mathrm{~km}$ do litoral brasileiro, encontram- se (Rodrigues, 2011):

- todas as refinarias de petróleo, exceto a Refinaria de Manaus que se situa à beira do rio Amazonas,

- 95\% de toda produção industrial,

- $87 \%$ do consumo de energia elétrica,

- 83\% da população do país e

- $78 \%$ de todas as receitas da União.

\section{4 . \\ O Estudo de Desempenho dos Portos e Terminais}

A partir dos anos 2000, o aumento das transações internacionais, o surgimento de novas tecnologias e uma maior participação do capital privado, além do desenvolvimento dos portos, acarretaram em um maior interesse no meio acadêmico sobre portos e terminais (Pallis et al., 2010).

Segundo Bichou (2007), os estudos de desempenho dos portos podem ser divididos em três principais categorias: indicadores e métricas, estudos dos impactos econômicos e análise da fronteira de eficiência.

Os indicadores e métricas visam quantificar um ou vários atributos de um objeto, produto ou processo e deve permitir a comparação e avaliação vis-à-vis objetivos e pontos de referência. Dependendo do alcance e natureza dos insumos e produtos selecionados e da metodologia utilizada para calcular, pode ser dividido em três tipos de medição: medidas de produtividade financeira, indicadores individuais e parciais de produtividade. Artigos sobre esses métodos podem se encontrados em Fourgeaud (2000) e Lawrance e Richards (2004).

Nos estudos dos impactos econômicos, os portos são vistos como catalisadores econômicos para as regiões que servem, e são avaliados os 
impactos econômicos e sociais dos portos em suas respectivas zonas de influência. São utilizados modelos de equações lineares, de equilíbrio computacional ou modelos gravitacionais. Além destes fatores, se avalia a eficiência dos portos em relação ao transporte e aos custos de logística com ênfase no papel dos portos no desenvolvimento do comércio. Para maiores informações: ver em Castro e Coto Millan (1998); Accario (2008); Guerrero et al. (2008) e Pizzolato et al. (2010).

A análise da fronteira de eficiência é representada por um limite que o porto deve atingir para ser considerado eficiente. A fronteira pode ser absoluta ou relativa (ou seja, as melhores práticas), dependendo do método de construção: paramétrico ou métodos não paramétricos.

De acordo com González e Trujillo (2009), o estudo da eficiência em portos se torna mais difícil devido à sua complexidade de organização com muitos processos e agentes envolvidos. As atividades e tipos de serviços diferenciamse devido à natureza da operação atribuída ao porto, função do porto e grau de competição do ambiente e regulamentações em que o porto se encontra. Por isso é mais indicado centralizar os estudos em uma única atividade do porto ou tipo de mercadoria do que um conjunto limitado de portos com atividades diversas.

Já quando são considerados somente os estudos de Terminais, os temas podem ser divididos em: medidas de desempenho, operação do terminal e descrição de estratégias (Pallis et al., 2010). Dentro destes temas as principais ferramentas utilizadas são de fronteira de eficiência, uma não paramétrica, DEA e outra paramétrica, Stochastic Frontier Analysis (SFA). Estas técnicas também foram aplicadas por alguns autores no estudo de governança e políticas portuárias. Os principais motivos para essa predominância seria o fato de terem um propósito específico e serem mais apropriadas a utilizarem dados obtidos através de pesquisas associados a modelos matemáticos, (Woo et al., 2011).

Dentre as técnicas de fronteira de eficiência mais usadas nos estudos de Portos, não existe um consenso sobre a melhor técnica (Panayides, 2009; González e Trujillo, 2009).

Cullinane et al. (2006b) atestaram que para os mesmos dados o ranking de classificação das técnicas DEA e SFA são os mesmos.

Neste estudo optou-se por empregar a técnica DEA devido ao fato de não utilizar uma função pré-determinada que relacione os insumos com os produtos. Além disso, a técnica DEA permiti fazer uma comparação da eficiência operacional dos terminais sem utilizar variáveis de custo operacional ou de lucro 
financeiro dos terminais. No próximo capítulo serão apresentadas as principais considerações sobre a técnica DEA aplicada aos portos e terminais.

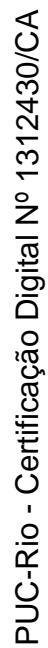




\section{4.}

\section{Abordagens de DEA no setor Portuário.}

Neste capítulo, serão feitas algumas considerações na modelagem com DEA aplicadas à eficiência de portos e serão apresentados os principais artigos de DEA relacionados aos portos. Dá-se destaque aos artigos que avaliam os portos brasileiros e, no final do capítulo, será apresentada uma tabela com os insumos e produtos utilizados nestes artigos.

\section{1. Modelagem com DEA aplicada a Portos e Terminais}

Os estudos da eficiência de portos com DEA são relativamente novos. A literatura indica que os primeiros são de 1993 por Roll e Hayuth, que trabalharam com dados hipotéticos e demonstraram como suas eficiências poderiam ser mensuradas. No Brasil, o primeiro estudo de DEA com portos de destaque foi de Rios e Maçada (2006). Além dos autores nacionais, o país vem despertando interesse da comunidade acadêmica em outros países como: Wu e Goh (2010); Oliveira e Cariou (2011) e Barros et al. (2012).

Já Merk e Dang (2012) argumentam que, apesar da movimentação de cargas a granel serem $65 \%$ do total movimentado nos vinte maiores portos europeus contra $27 \%$ da movimentação de contêineres, a maior parte da literatura concentra-se no estudo de portos ou terminais de contêineres. Neste estudo além dos artigos de contêineres, são citados artigos que consideram cargas a granel como: Pires et al. (2009), Oliveira e Cariou (2011), Merk e Dang (2012) e Wanke e Mattos (2014).

\subsection{1.}

\section{Modelo de Formulação}

Segundo Panayides et al. (2009), não existe nenhuma teoria robusta sobre o melhor modelo de DEA que deve ser aplicado, CCR ou BCC, na avaliação dos portos. Inclusive se os portos apresentam retorno constante ou variável. Entretanto, Cullinane et al. (2006) concluem que, para somente se identificar a 
eficiência técnica devido à economia de escala, o modelo BCC seria mais indicado.

\section{Orientação}

Para Wang et al. (2003) e Cullinane et al. (2006), os modelos orientados ao insumo são mais indicados aos problemas operacionais, enquanto os modelos orientados ao produto estariam relacionados ao planejamento estratégico. Os autores explicam essa teoria através de uma correlação entre as principais características de um terminal: ser enxuto e ágil aos problemas operacionais e de planejamento respectivamente.

\subsection{2.}

\section{Seleção dos Insumos e Produtos}

$\mathrm{Na}$ formulação do modelo deverão ser levados em consideração os objetivos dos portos que podem ser afetados não só por fatores externos como também por políticas e culturas internas. A não consideração disto pode levar a uma conclusão tendenciosa, (Panayides et al., 2009).

Nos estudos com DEA em portos, a maioria dos insumos selecionados está relacionada com o uso de mão de obra, espaço ou equipamentos. Isto é exemplificado em alguns trabalhos que utilizam como insumo: números de empregados, horas trabalhadas, despesas com salários, número de cranes, berços, profundidade de calado etc. (Wu e Goh, 2010).

Já a quantidade de carga movimentada é o produto mais largamente utilizado nos estudos de portos com DEA, (González e Trujillo, 2009; Panayides et al., 2009). As principais razões para uso desse fator, especialmente para terminais de contêineres, são: a facilidade de obtenção dos dados, ser um fator de determinação do tamanho do porto, de medir a necessidade de novas instalações e base para a geração de receita (Cullinane e Wang, 2006).

A utilização somente da movimentação como produto pode não refletir a eficiência total do porto, podendo ignorar outros aspectos como market-share e satisfação do cliente, muito embora este último atributo, por ser intangível, possa ser difícil de quantificar e/ou conseguir dados confiáveis, (Panayides et al., 2009). Segundo González e Trujillo (2009), a atividade portuária mostra uma característica de apresentar multiprodutos. Ao considerar multiprodutos os estudos com DEA apresentariam uma vantagem em relação aos estudos SFA. 
Segundo Panayides et al. (2009), uma análise do processo de produção é suficiente na escolha dos insumos e produtos. Um aumento no número de fatores que caracterizam a produção de um porto levará a uma redução no poder de discriminação da técnica DEA. Panayides et al. (2009), argumentam que, conforme se aumenta o número de fatores, a possibilidade de um porto tornar-se eficiente em um diferente fator também aumenta, consequentemente encontramos mais DMUs eficientes. Ou seja, a seleção ideal é aquela com menor número de insumos e produtos que melhor caracterizam todo o processo operacional dos portos em análise e deve estar alinhada com o número de portos.

González e Trujillo (2009) destacam que, na falta de dados, alguns autores fazem aproximações em suas análises da eficiência como: considerar os empregados da autoridade portuária em vez de estivadore (ex.: Tongzon, 2001; Martin, 2002), considerar dados do porto quando se quer comparar um terminal em específico (ex.: Cullinane et al., 2004). Segundo González e Trujillo (2009), estas confusões podem levar a erros de conclusão.

Nos estudos de Panayides et al. (2009), que revisaram os principais artigos de análise da eficiência de portos com DEA, o número de insumos está entre 2 e 7 com uma média de 4,2. O número de produtos está entre 1 e $6 \mathrm{com}$ uma média de 2,3. Já a quantidade de portos ou terminais analisados é de 6 a 104 com uma média de 28.

Quando se faz uma análise Cross-Seccional, isto é, pontual em relação ao tempo e não ao longo do tempo, os resultados podem conter viés decorrente de situações específicas para o período analisado (González e Trujillo, 2009). Apesar dessa limitação, esse recurso foi utilizado por alguns autores: Tongzon (2001); Park e De (2004) e Cullinane e Wang (2006). Cullinane et al. (2005a) indicam a utilização de panel data para contornar essa limitação.

$\mathrm{Na}$ análise de eficiência com DEA, um insumo ou um produto pode ser mais importante para uma DMU que para outra. Essa característica é mais acentuada em relação aos portos, onde diferentes fatores exercem papéis diferentes na avaliação de cada porto. Isto é, os insumos e produtos vão ser mais ou menos importantes, conforme a atividade ou objetivo de cada porto (Panayides et al., 2009).

Através da análise dos preços-sombra e/ou das folgas, é possível determinar que mudanças nos insumos e produtos analisados exercem maior influência sobre a eficiência de qualquer porto ou terminal, determinando assim a origem da ineficiência, (Cullinane et al., 2006). 


\subsection{3. \\ Seleção dos Portos}

De acordo com Panayides et al. (2009), um tamanho de amostra elevado (grande número de portos) garante que os fatores podem ser selecionados de forma mais abrangente, capturando assim a complexidade de produção dos portos.

Uma proposição na seleção dos portos a serem escolhidos pode ser baseada na estrutura do mercado. Os portos podem ser analisados em uma perspectiva de um país ou na competição entre portos individualmente. A competição entre portos está relacionada: à área de influência que possuem, à posição geográfica ou ao tipo de mercadoria na qual movimentam.

Alguns terminais podem se diferenciar dos demais devido a fatores externos à sua responsabilidade. Como exemplos desta diferença, citamos: um porto oceânico que recebe movimentação de cabotagem além de realizar exportações e importações, um porto fluvial onde o acesso e porte dos navios são limitados a altura do calado e um porto que atende a uma refinaria, por trabalhar com cargas líquidas que apresentam operações cargas e descargas rápidas, necessidade de pouca estrutura de equipamentos e, além disso, apresentam um fluxo elevado de navios, (González e Trujillo, 2009).

Segundo Wang et al. (2002) e Cullinane et al. (2004), os estudos que consideram somente terminais possibilitam uma comparação melhor. Panayides et al. (2009) destacam que o número limitado de estudos com terminais deve-se ao fato da falta de padronização dos dados e da dificuldade em obter os dados.

González e Trujillo (2009) justificam a teoria de se comparar terminais para um tipo específico de produto, a fim de garantir a homogeneidade, devido à complexidade dos portos que apresentam diferentes tipos de atividades e serviços.

Segundo Cullinane et al. (2006) a modelagem DEA não possui quaisquer suposições estatísticas ou propriedades por si só. É necessário ter em mente que DEA é uma técnica que compara a eficiência relacionada às melhores práticas de um conjunto de portos selecionados, portanto não faz sentido a comparação do resultado da eficiência entre diferentes estudos (Panayides et al., 2009). 


\section{2.}

\section{Artigos em DEA com portos}

Nesta seção, apresentamos os principais estudos de DEA aplicados aos portos e terminais internacionais.

O artigo de Roll e Hayuth (1993) é considerado um marco e um trabalho pioneiro na defesa da aplicação de DEA ao contexto da produção portuária. Apesar da abordagem com dados hipotéticos, em vez de uma aplicação mais concreta, destacam-se a utilização de satisfação do cliente e nível de serviço, além da movimentação de clientes como produtos.

Martinez-Budria et al. (1999) classificaram um total de 26 portos de contêineres na Espanha entre 1993 e 1997. Investigaram as diferenças em relação ao tamanho dos portos e seus produtos, separando em três grupos: alta, média e baixa complexidade. Depois de examinar a eficiência desses portos utilizando modelos DEA-BCC, os autores concluíram que os portos de alta complexidade estão associados com alta eficiência, em comparação com a eficiência média e baixa encontrada nos outros grupos de portos.

Tongzon (2001) utilizou-se de modelos DEA-CCR e DEA-Aditivo com o objetivo de analisar a eficiência de quatro portos australianos e 12 portos de contêineres internacionais, para o ano de 1996. Ele concluiu que, além do tamanho e das funções desempenhadas, outras características devem ser consideradas. Concluiu também que o número de portos em análise pode influenciar no resultado.

Em 1998, Valentine e Gray (2001) aplicaram o modelo DEA-CCR a 31 portos de contêineres entre os 100 maiores do Mundo. O objetivo do trabalho foi comparar a eficiência de diferentes portos em relacionando com os tipos de propriedades e estrutura organizacional e concluíram que uma análise de Clusters seria uma ferramenta útil para identificar estruturas organizacionais diferentes.

Para o período 1990-1998, Itoh (2002) realizou uma análise na qual foi aplicado o modelo DEA Window Analysis, relacionado com oito portos de contêineres internacionais do Japão. Recomendaram que a extensão da janela tivesse o máximo possível de DMUs.

Barros (2003a) investigou se as autoridades portuárias portuguesas atingiam seu objetivo de incentivar o aumento de eficiência dos portos através de subsídios. Aplicou DEA ao setor portuário de movimentação de contêineres, no período de 1999 a 2000. Ele concluiu que os incentivos regulatórios 
estabelecidos foram bem sucedidos na promoção do aprimoramento da eficiência do setor, mas que isso poderia ser melhorado através da aplicação de recomendações destinadas à redefinição do papel da Agência PortuárioMarítima Portuguesa (órgão regulador responsável por questões portuárias).

Barros (2003b) utilizou dados referentes ao período de 1990 a 2000, aplicando DEA ao setor portuário português a fim de estimar a eficiência de onze portos portugueses e identificar suas ineficiências. Concluiu-se que os investimentos financeiros, que fazem parte do programa de mercado comum da União Europeia (UE), estimularam uma maior eficiência no setor portuário, particularmente como resultado de uma maior concorrência enfrentada pelos portos de Portugal localizados perto da fronteira com a Espanha. Através da aplicação de Regressão Tobit, Barros (2003b) verificou que os terminais especializados na movimentação de contêineres são mais eficientes do que os portos que trabalham com múltiplas cargas. Também se concluiu que a maior eficiência está intimamente ligada ao market-share do porto.

Barros e Athanassiou (2004) aplicaram DEA para analisar a eficiência de dois portos da Grécia e quatro de Portugal. Utilizaram dados por painel entre 1998 e 2000. O objetivo deste trabalho era determinar benchmarks para os portos, indicando as melhorias de práticas de gestão e reconheceram que a amostra foi curta. Finalmente, concluem que a aplicação desta forma de benchmarking pode gerar de fato benefícios econômicos para os portos.

Bonilla et al. (2004) analisaram 23 portos espanhóis entre 1995 e 1998 em um modelo de DEA-bootstrapping, devido aos portos movimentarem mais de um tipo de carga. Usando uma Análise de Sensibilidade, foram identificados os portos que eram mais sensíveis às variações nos volumes de tráfego entre os diferentes tipos de cargas manipuladas.

Park e De (2004), aplicaram em onze portos coreanos um método alternativo de DEA em quatro fases, em que a eficiência era dividida em estágios: produtividade, rentabilidade, comercialização e global. Os produtos do primeiro estágio foram considerados como insumos do segundo estágio e assim por diante. Investigaram também um conceito econômico chamado de congestionamento de insumos. Concluíram que a melhoria da comercialização dos portos deveria ser a prioridade máxima das autoridades portuárias coreanas.

Cullinane et al. (2004) analisaram 25 portos pelo mundo utilizando dados cross-seccion e panel data. Sugeriram que a comparação entre terminais seria mais adequada para cotejar o porto inteiro. Identificaram que os portos de contêineres apresentam retornos constantes de escala, porém não seria um fator 
de ineficiência. Concluíram que ao aplicar essas duas abordagens DEA, comparando seus resultados, a evolução da eficiência de cada porto ou terminal pode ser estudada ao longo do tempo, sendo possível alcançar conclusões mais convincentes.

Turner et al. (2004), com o objetivo de avaliar a relação entre produtividade e a infraestrutura, aplicaram DEA para avaliar a eficiência de 26 portos dos Estados Unidos da América e do Canadá, no período de 1984 a 1997. Foi também utilizada a estimativa de produtividade como a variável dependente em um modelo de Regressão de Tobit, que procurou determinar os fatores causais que afetavam os escores derivados da análise DEA. Verificaram a existência de importantes economias de escala presentes no setor de contêiner norteamericano, e concluíram que o acesso à rede ferroviária é um determinante essencial da produtividade relacionada à infraestrutura dos portos que movimentam contêineres naquele país.

Cullinane et al. (2005a) analisaram os 30 maiores portos de contêineres do mundo no que se refere à privatização e à eficiência relativa dentro do setor portuário. Concluíram a superioridade do uso do panel data ao cross-section data e rejeitaram a hipótese que envolvimento privado do setor portuário conduz à melhoria da eficiência.

Cullinane et al. (2005b) usaram um conjunto de dados para os 57 terminais de contêineres mais importantes do mundo em 2001, comparando as eficiências relativas derivadas da aplicação de DEA e da técnica Free Disposal Hull (FDH). Os resultados gerados foram diferentes de acordo com cada metodologia de programação empregada. Concluiu-se que a definição adequada das variáveis de entrada e saída dos modelos é um elemento crucial para a aplicação dessas técnicas.

Cullinane et al. (2006) aplicaram DEA e Análise de Fronteira Estocástica Stochatic Frontier Analysis (SFA) a um conjunto formado pelos 57 maiores terminais contêineres do Mundo. Comparando-se os resultados obtidos, encontrou-se um elevado grau de correlação entre as estimativas de eficiência derivadas dos dois modelos aplicados, sugerindo que os resultados são relativamente sólidos e coerentes, tanto para os modelos DEA quanto para os modelos SFA. Por fim, observaram que uma análise usando panel data seria mais apropriada nos estudos da eficiência relativa dos portos internacionais.

Cullinane e Wang (2006) analisaram 69 terminais europeus com movimentação anual superior a 10.000 TEUs, para o ano de 2002. A maioria dos terminais em estudo apresentou retornos de escala crescentes, com os maiores 
terminais sendo associados aos mais altos escores de eficiência. Concluíram também que existiam variações significativas da eficiência média de terminais situados em regiões diferentes.

Sharma e Yu (2008) verificaram que a aplicação tradicional de DEA poderia gerar resultados tendenciosos em razão do conjunto de DMUs de uma amostra poder apresentar grandes diferenças em relação ao tamanho, ambiente e práticas operacionais. Com o intuito de superar essa problemática, fundiram DEA a uma técnica de Data Mining chamada Self-Organization Map (SOM). DEA foi utilizada para estratificar os portos em camadas de eficiência, e SOM foi utilizado para classificar esses portos de contêineres em grupos mais homogêneos, de acordo com suas capacidades máximas e suas propriedades similares de inputs. Foram criados assim benchmarks mais coerentes com a realidade, baseados nas camadas de eficiência geradas por DEA.

Merk e Dang (2012) utilizaram DEA-bootstrapping para analisar os maiores portos do mundo separando por tipo de carga: petróleo, carvão, minérios, grão e contêiners. Em relação aos portos de petróleo, consideraram 71 portos na Ásia, Europa e América do Norte. Concluíram que os portos de contêineres e de petróleo utilizam a tecnologia mais eficientemente que os demais portos, provavelmente devido a pressões externas. Os portos de petróleo, minério de ferro e de grãos têm uma eficiência maior conforme aumenta o tamanho do porto. Os terminais de transbordo de petróleo do Golfo foram considerados os mais eficientes entre os portos de petróleo.

Bichou (2013) analisou 60 terminais contêineres entre 2004 e 2010. Foram utilizados os modelos DEA-CCR e DEA-BCC com orientação ao insumo. Os dados foram analisados com visão cross-sectional e panel data. O objetivo era descobrir qual a relação entre tamanho do terminal, índice de transbordos, proporção da variedade de cargas e tipo de equipamentos, políticas e procedimentos operacionais e a eficiência. Concluíram que os terminais apresentaram variação de retorno de escala, que a variação da carga influencia na eficiência e que sistemas automáticos tendem a melhorar a eficiência.

\subsection{1.}

\section{Aplicações de DEA a portos do Brasil:}

Nesta seção apresentamos os principais estudos de DEA aplicados ao portos e terminais brasileiros. 
Rios e Maçada (2006) mediram e avaliaram a eficiência relativa dos terminais de contêineres do Mercosul, sendo 10 no Brasil, 3 na Argentina e 1 no Uruguai, entre 2002 e 2004, utilizando DEA BCC e Regressão Tobit. Destacam-se por apresentarem dados obtidos através de entrevista em vez de base de dados. Concluíram que os terminais eficientes podem ser considerados referências e suas práticas podem ser usadas nos demais terminais.

Fontes e Soares de Mello (2006) utilizaram DEA para avaliar a eficiência de portos brasileiros no período entre 2002 e 2004. São considerados 31 portos e terminais e três modelos, físico, financeiro e físico-financeiro. Neste estudo, verificam que o terminal salineiro de Areia Branca foi o mais eficiente dentre os portos analisados e que os modelos utilizados não são os mais adequados para avaliar a eficiência do porto de Santos.

Pires et al. (2009) aplicaram DEA para analisar a eficiência de 14 portos de exportação de minério de ferro. Eles consideraram os resultados obtidos consistentes e representativos, uma vez que os portos eficientes segundo o modelo estão localizados no Brasil e na Austrália, os dois maiores países exportadores de minério de ferro do mundo.

Wu e Goh (2010) compararam 21 portos de países emergentes, BRIC (Brasi, Russia, India e China) e Next-11, com os países desenvolvidos pertencentes ao G7 (Estados Unidos, Reino Unido, França, Alemanha, Itália, Canadá e Japão). Foi selecionado o maior porto de contêiner de cada país, Santos no caso do Brasil. Os resultados de eficiência foram divididos em três grupos. Consideraram que os portos de Bangladesh, China e Brasil podem ser tidos como referência para os demais e que os portos dos países do G7 tiveram os piores resultados.

Acosta et al. (2011) aplicaram DEA-BCC com técnica de regiões seguras Cone Ratio, em 27 portos brasileiros com o objetivo de identificar benchmarks em portos brasileiros utilizando DEA. Concluíram que $51,9 \%$ dos portos investigados podem aumentar a quantidade de carga movimentada em pelo menos $200 \%$. Os portos considerados ineficientes também possuíam folgas residuais em relação aos insumos, indicando condições de captarem mais cargas. Essa captação de cargas estava relacionada com a posição geográfica, com a aquisição e/ou com a modernização dos equipamentos.

Bertoloto e Soares de Mello (2011), usando DEA BCC, analisaram 48 portos brasileiros com características específicas, no período de 2007 a 2009. Os portos foram separados em quatro clusters distintos (misto, granel liquido, granel sólido e carga geral). Depois então, para avaliar todos os portos, foi usada 
uma técnica de homogeneidade. Concluíram que as eficiências de alguns terminais foram impactadas negativamente, como os operados pela mineradora, pela crise econômica internacional que se iniciou no terceiro trimestre de 2008. O setor petrolífero não foi atingido pela crise mundial. A técnica apresentada permitiu a comparação de portos distintos e se pressupõem para a homogeneização, que as DMUs eficientes de cada cluster possuem boa gestão.

Wanke et al. (2011) avaliaram 25 terminais brasileiros, utilizando SFA e DEA. Concluíram que a maioria dos terminais brasileiros está com falta de capacidade devido ao boom de exportações que tem ocorrido ao longo dos últimos anos e devido à falta de investimento em expansão de capacidade. Os terminais controlados pelo setor privado tendem a ser mais eficientes que os controlados pelo governo. Utilizando um modelo reduzido com apenas uma entrada e uma saída, foram explicadas com base em variáveis como o tipo de carga movimentada (recipiente ou a granel), a conectividade do terminal para estradas de ferro.

Oliveira e Cariou (2011) analisam a eficiência de 122 terminais de carvão e ferro, incluindo sete brasileiros, em 2005. Identificam os insumos e produtos mais relevantes quando aplicados a terminais a granel, devido ao fato de não haver uma homogeneidade em relação os terminais de carvão e de ferro. Apresentam um estudo comparando a eficiência em relação aos países dos portos. Concluem que a ineficiência está relacionada com a escala

Barros et al. (2012) analisaram 23 portos públicos brasileiros entre 2004 e 2010, utilizando DEA e Índice Malmquist. O método tradicional de crescimento contábil, que assume mudanças tecnológicas Hicks-neutral não foi adequado para a análise dos portos brasileiros. Eles concluíram que é necessário aumentar a produtividade, investindo em tecnologia e que não existe uma política comum de gerenciamento.

Cortez et al. (2013) avaliaram o desempenho gerencial de oito autoridades portuárias brasileiras, entre 2007 a 2008. Utilizaram DEA BCC e CCR com o método de avaliação cruzada. Observaram o efeito da crise de 2008 sobre as operações portuárias e concluíram que há necessidade de o governo aprimorar a infraestrutura provida, de modo a acabar com o gargalo logístico existente no entorno dos portos, aumentando assim o grau de competitividade da indústria nacional.

Wanke (2013) usou DEA com duas fases para melhor caracterizar as operações internas dos portos. A primeira considerava a estrutura física e a segunda a eficiência de embarque. Um modelo de eficiência de rede 
centralizada foi adotado para otimizar ambas as fases simultaneamente. Concluiu que as diferenças de: tipo de administração (pública ou privada), tamanho da área de influência e tipo de mercadoria têm impactos na infraestrutura física e na eficiência de embarque.

Sousa Júnior et al. (2013) avaliaram 16 terminais da região nordeste do país, sendo 11 públicos e 5 privados que movimentavam contêineres e granéis. Utilizaram o método CNU proposto por Angulo-Meza (2007) para seleção das variáveis. Sousa Júnior et al. (2013) concluíram que a infraestrutura e os equipamentos não atendiam adequadamente aos navios e que o aumento da profundidade de calado poderia aumentar o desempenho dos terminais.

Wanke e Mattos (2014) utilizaram DEA com a técnica de bootstrapping para avaliar 53 terminais graneleiros no Brasil. Concluíram que a maioria dos terminais graneleiros brasileiros apresentam retornos de escala crescente, ou seja, eles são muito pequenos em tamanho, comparativamente às tarefas realizadas, indicando um déficit de capacidade. Também concluíram que os terminais fluviais eram mais eficientes que os marítimos, devido a sua especialização em carregamento de soja. As técnicas utilizadas foram eficientes em determinar as diferenças entre os terminais.

Conforme pode se observar nos artigos acima, a contribuição deste último trabalho se diferencia dos demais ao comparar somente a eficiência de terminais brasileiros de petróleo e seus derivados.

Através dos estudos citados neste capitulo pode se determinar quais insumos e produtos deveriam ser empregados neste estudo.

Sintetizando a revisão da literatura, o Quadro 1 apresenta os trabalhos internacionais e o Quadro 2, os trabalhos nacionais que utilizaram a metodologia DEA para avaliar a eficiência dos portos: 


\begin{tabular}{|c|c|c|c|}
\hline Autores & Método & Insumos & Produtos \\
\hline Roll e Hayuth (1993) & DEA-CCR & $\begin{array}{l}\text { - total de capital investido } \\
\text { - número de funcionários } \\
\text { - tipo de carga }\end{array}$ & $\begin{array}{l}\text {-nível de serviço } \\
\text {-movimentação de carga } \\
\text {-satisfação dos usuários } \\
\text {-número de atracações }\end{array}$ \\
\hline Marinez-Budria et al. (1999) & DEA-BCC & $\begin{array}{l}\text { - despesas com pessoal } \\
\text { - taxas de depreciação } \\
\text { - outros gastos }\end{array}$ & $\begin{array}{l}\text {-total de carga movimentada. } \\
\text {-receita obtida no aluguel de } \\
\text { utilidades. }\end{array}$ \\
\hline Tongzon (2001) & DEA-CCR e Aditivo & $\begin{array}{l}\text { - número de empregados } \\
\text { - número de berços } \\
\text { - número de guindastes } \\
\text { - número de rebocadores } \\
\text { - tempo de atraso } \\
\text {-área do terminal }\end{array}$ & $\begin{array}{l}\text { - total de contêineres mov.(TEU) } \\
\text { - quantidade movimentada/ (hora. } \\
\text { navio) }\end{array}$ \\
\hline Valentine e Gray (2001) & DEA-CCR & $\begin{array}{l}\text { - comprimento do berço } \\
\text { - total investido }\end{array}$ & $\begin{array}{l}\text { - número de contêineres } \\
\text { movimentados } \\
\text {-volume movimentado. }\end{array}$ \\
\hline Itoh (2002) & $\begin{array}{l}\text { DEA- CCR } \\
\text { DEA-BBC }\end{array}$ & $\begin{array}{l}\text {-área do terminal } \\
\text {-número de berços } \\
\text {-número de guindastes } \\
\text {-número de empregados }\end{array}$ & - quantidade movimentada ( TEU) \\
\hline
\end{tabular}




\begin{tabular}{|c|c|c|c|}
\hline Autores & Método & Insumos & Produtos \\
\hline Barros (2003a) & $\begin{array}{l}\text { DEA- CCR } \\
\text { DEA -BBC }\end{array}$ & $\begin{array}{l}\text {-número de empregados } \\
\text {-capital ( valor líquido do porto) }\end{array}$ & $\begin{array}{l}\text { - número de atracações } \\
\text { - circulação de carga } \\
\text {-tonelagem bruta } \\
\text { - market share } \\
\text {-contêineres movimentados. } \\
\text {-carga-geral movimentada } \\
\text {-carga líquida } \\
\text {-carga seca } \\
\text {-tráfego Ro/Ro } \\
\text {-rendimento líquido }\end{array}$ \\
\hline Barros (2003b) & $\begin{array}{l}\text { DEA- Regressão } \\
\text { Tobit }\end{array}$ & $\begin{array}{l}\text {-número de empregados } \\
\text {-capital (valor líquido do porto) }\end{array}$ & $\begin{array}{l}\text { - número de atracações } \\
\text { - circulação de carga } \\
\text {-capacidade bruta de carga dos } \\
\text { navios } \\
\text { - market share } \\
\text {-contêineres movimentados } \\
\text {-carga-geral movimentada } \\
\text {-granéis líquidos movimentados } \\
\text {-granéis sólidos movimentados }\end{array}$ \\
\hline Barros e Athanassiou (2004) & $\begin{array}{l}\text { DEA- CCR } \\
\text { DEA -BBC }\end{array}$ & $\begin{array}{l}\text {-n de empregados } \\
\text {-capital (valor líquido do porto) }\end{array}$ & $\begin{array}{l}\text { - número de atracações } \\
\text { - circulação de carga } \\
\text {-contêineres movimentados. } \\
\text {-carga-geral movimentada }\end{array}$ \\
\hline Bonilla et al. (2004) & $\begin{array}{l}\text { DEA-BCC } \\
\text { bootstrapping }\end{array}$ & -capital investido em equipamentos & $\begin{array}{l}\text {-Total em toneladas movimentadas } \\
\text { por tipo de carga }\end{array}$ \\
\hline
\end{tabular}




\begin{tabular}{|c|c|c|c|}
\hline Autores & Método & Insumos & Produtos \\
\hline Cullinane et al. (2004) & $\begin{array}{l}\text { DEA - CCR } \\
\text { DEA - BBC }\end{array}$ & $\begin{array}{l}\text {-tamanho de berço } \\
\text {-área do terminal } \\
\text {-número de guindaste no berço } \\
\text {-número de guindaste no pátio } \\
\text {-número de Straddle Carrier }\end{array}$ & - quantidade movimentada (TEU) \\
\hline Park e De (2004) & $\begin{array}{l}\text { DEA- CCR } \\
\text { DEA-BBC }\end{array}$ & $\begin{array}{l}\text {-capacidade dos berços } \\
\text {-capacidade de manuseio da carga }\end{array}$ & $\begin{array}{l}\text { - movimentação de carga } \\
\text { - número de navios } \\
\text { - rentabilidade } \\
\text { - satisfação do cliente }\end{array}$ \\
\hline Turner et al. (2004) & DEA - regressão Tobit & $\begin{array}{l}\text { - área do terminal } \\
\text { - número de guindastes } \\
\text { - comprimento do berço }\end{array}$ & - quantidade movimentada (TEU) \\
\hline Cullinane et al. (2005a) & $\begin{array}{l}\text { DEA- CCR } \\
\text { DEA -BBC } \\
\text { FDH }\end{array}$ & $\begin{array}{l}\text {-comprimento do terminal } \\
\text {-área do terminal } \\
\text {-número de guindastes de Cais } \\
\text {-número de guindastes de pátio } \\
\text {-número de Straddle Carriers }\end{array}$ & - quantidade movimentada (TEU) \\
\hline Cullinane et al. (2005b) & $\begin{array}{l}\text { DEA- CCR } \\
\text { DEA-BBC }\end{array}$ & $\begin{array}{l}\text {-comprimento do terminal } \\
\text {-área do terminal } \\
\text {-número de guindastes de Cais } \\
\text {-número de guindastes de pátio } \\
\text {-número de Straddle Carriers }\end{array}$ & - quantidade movimentada (TEU) \\
\hline
\end{tabular}




\begin{tabular}{|c|c|c|c|}
\hline Autores & Método & Insumos & Produtos \\
\hline Cullinane e Wang (2006) & $\begin{array}{l}\text { DEA- CCR } \\
\text { DEA -BBC }\end{array}$ & $\begin{array}{l}\text {-comprimento do terminal } \\
\text {-área do terminal } \\
\text {-número de equipamentos }\end{array}$ & - quantidade movimentada (TEU) \\
\hline Cullinane e Wang (2006) & $\begin{array}{l}\text { DEA- CCR } \\
\text { DEA -BBC }\end{array}$ & $\begin{array}{l}\text {-comprimento do terminal } \\
\text {-área do terminal } \\
\text {-número de equipamentos de Cais } \\
\text {-número de equipamentos de pátio } \\
\text {-número de Straddle Carriers }\end{array}$ & - quantidade movimentada (TEU) \\
\hline Sharma e Yu (2008) & CCR & $\begin{array}{l}\text {-comprimento do terminal } \\
\text {-área do terminal } \\
\text {-número de guindastes de cais } \\
\text {-número de guindastes de pátio } \\
\text {-número de Straddle Carriers } \\
\text {-número de Reach Stackers }\end{array}$ & - quantidade movimentada (TEU) \\
\hline Merk e Dang (2012) & $\begin{array}{c}\text { DEA } \\
\text { bootstrapped }\end{array}$ & $\begin{array}{l}\text { - comprimento do berço } \\
\text { - capacidade máxima do navio (dwt) } \\
\text { - profundidade do canal } \\
\text { - capacidade de armazenagem } \\
\text { - velocidade de descarga } \\
\text { - diâmetro da tubulação do píer }\end{array}$ & -quantidade movimentada (dwt) \\
\hline
\end{tabular}




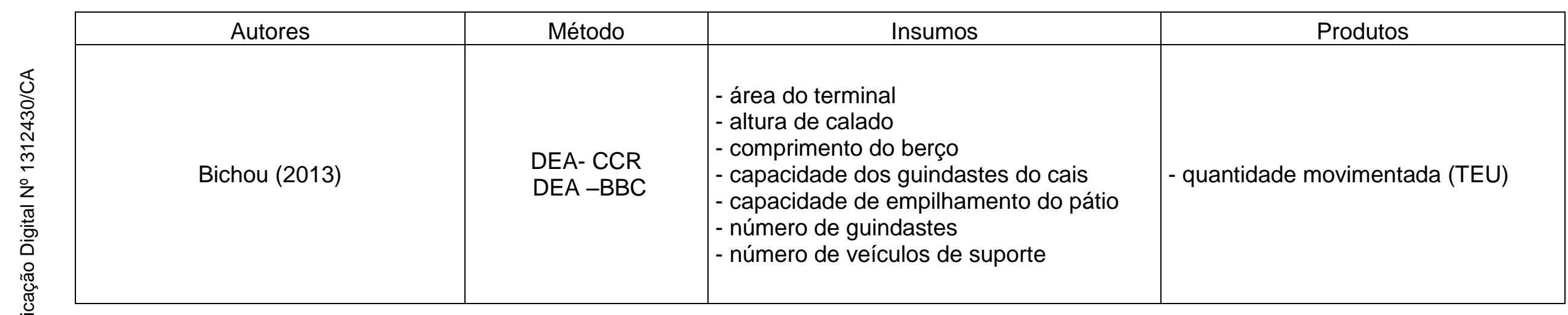

Quadro 1- Aplicações de DEA a portos internacionais

Fonte: Autor 


\begin{tabular}{|c|c|c|c|}
\hline Autores & Método & Insumos & Produtos \\
\hline Rios e Maçada (2006) & $\begin{array}{l}\text { DEA- CCR } \\
\text { DEA-BBC }\end{array}$ & $\begin{array}{l}\text { - número de guindastes } \\
\text { - número de berços } \\
\text { - número de equipamentos } \\
\text { - número de funcionários } \\
\text {-área do terminal }\end{array}$ & $\begin{array}{l}\text { - quantidade movimentada (TEU) } \\
\text { - quantidade movimentada/ (hora/ navio) }\end{array}$ \\
\hline Fontes e Soares de Mello (2006) & DEA- BCC & - extensão do cais & $\begin{array}{l}\text { - número de navios } \\
\text { - quantidade movimentada }\end{array}$ \\
\hline Pires et al. (2009) & $\begin{array}{l}\text { DEA- CCR } \\
\text { DEA-BBC }\end{array}$ & $\begin{array}{l}\text { - calado do berço } \\
\text { - comprimento do berço } \\
\text { - largura do berço }\end{array}$ & - movimentação anual de carga \\
\hline Wu e Goh (2010) & $\begin{array}{l}\text { DEA- CCR } \\
\text { DEA -BBC }\end{array}$ & $\begin{array}{l}\text {-área do terminal } \\
\text { - comprimento do berço } \\
\text { - número de equipamentos }\end{array}$ & - quantidade movimentada (TEU) \\
\hline Acosta et al. (2011) & $\begin{array}{l}\text { DEA- BCC } \\
\text { restrição de pesos } \\
\text { (região segura) }\end{array}$ & $\begin{array}{l}\text { - profundidade do canal } \\
\text { - extensão do cais } \\
\text { - área de armazenagem }\end{array}$ & - movimentação geral \\
\hline Bertoloto e Soares de Mello (2011) & DEA- BCC & $\begin{array}{l}\text {-extensão dos berços } \\
\text { - calado máximo }\end{array}$ & - volume total de cargas movimentadas \\
\hline Oliveira e Cariou (2011) & $\begin{array}{l}\text { DEA- CCR } \\
\text { DEA-BBC }\end{array}$ & $\begin{array}{l}\text {-comprimento do berço } \\
\text { - capacidade de armazenagem } \\
\text { - velocidade de carga/descarga }\end{array}$ & -quantidade movimentada anual \\
\hline Wanke et al. (2011) & $\begin{array}{l}\text { DEA- Regressão } \\
\text { Tobit }\end{array}$ & $\begin{array}{l}\text { - área do terminal } \\
\text { - área de estacionamento } \\
\text { - número de berços }\end{array}$ & $\begin{array}{l}\text {-movimentação total } \\
\text { - número de navios }\end{array}$ \\
\hline
\end{tabular}




\begin{tabular}{|c|c|c|c|}
\hline Autores & Método & Insumos & Produtos \\
\hline Barros et al. (2012) & $\begin{array}{l}\text { DEA - Índice } \\
\text { Malmquist }\end{array}$ & $\begin{array}{l}\text { - comprimento do berço } \\
\text { - número de cranes } \\
\text { - número de empregados }\end{array}$ & -quantidade movimentada \\
\hline Cortez et al. (2013) & $\begin{array}{l}\text { DEA- CCR } \\
\text { DEA -BBC }\end{array}$ & $\begin{array}{l}\text { - número de funcionários } \\
\text { - custo operacional } \\
\text { - investimento }\end{array}$ & $\begin{array}{l}\text {-faturamento } \\
\text {-carga movimentada }\end{array}$ \\
\hline Wanke (2013) & network-DEA & $\begin{array}{l}\text { - número de berços } \\
\text {-área de armazenagem } \\
\text {-área do pátio } \\
\text { - frequência de navios }\end{array}$ & -movimentação total \\
\hline Sousa Júnior et al. (2013) & DEA CCR & $\begin{array}{l}\text { - calado } \\
\text { - extensão de berço } \\
\text { - capacidade estática }\end{array}$ & $\begin{array}{l}\text { - número de navios } \\
\text { - quantidade movimentada (TEU) } \\
\text {-movimentação horária }\end{array}$ \\
\hline Wanke e Mattos (2014) & $\begin{array}{c}\text { DEA } \\
\text { bootstrapped }\end{array}$ & -número de horas de carga & $\begin{array}{l}\text { - movimentação total } \\
\text { - número de navios carregados }\end{array}$ \\
\hline
\end{tabular}

Quadro 2- Aplicações de DEA aos portos do Brasil

Fonte: Autor 


\section{5.}

\section{Aplicação de um Modelo de Análise de Envoltória.}

Neste capítulo, iremos apresentar o cenário do modelo proposto, caracterizar os terminais que serão analisados e justificar a escolha dos fatores de produção e dos modelos de DEA adotados.

\section{1.}

\section{Modelo e Fatores de produção utilizados}

Antes de realizar uma análise pelo método DEA, é necessário definir os terminais a serem comparados e classificados, as variáveis de insumo e de produto, bem como o modelo de formulação.

Após a caracterização dos terminais, nesta seção apresentam-se os critérios que nortearam a escolha dos terminais, as variáveis de insumo e produto e o modelo de DEA a ser adotado.

\subsection{1.}

Seleção dos terminais

O estudo compreende 16 terminais, sendo 2 na região Norte, 7 na região Nordeste, 4 na região Sudeste e 3 na região Sul. O número de terminais é compatível com os demais estudos de DEA, que segundo Panayides et al. (2009) está entre 6 e 104 DMUs, com uma média de 19,8, se desconsiderarmos o trabalho de Wang e Cullinane (2006).

Os terminais atendem o critério de homogeneidade, pois realizam as mesmas tarefas: atracação, inspeção do navio, medição e amostragem, liberação e desatracação. Têm o mesmo objetivo de atender ao seu mercado nas mesmas condições, com autonomia nas suas decisões.

\subsection{2.}

\section{Escolha das Variáveis}

Foi respeitada a relação de três vezes entre o número de DMUs e variáveis (Golany e Roll, 1989), a fim de que se possa ter uma boa discrepância 
de eficiências. Além disso, Tongzon (2001) recomenda selecionar fatores relacionados aos recursos humanos, investimento de capital, espaço e nível de serviço.

Foram selecionados três insumos: tempo de operação, mão de obra e número de berços, além de um produto: o volume total de produtos carregados e descarregados. Os dados referem-se ao ano de 2014 e foram obtidos nos bancos de dados da empresa ou por entrevistas com os coordenadores dos terminais.

Para o tempo de operação foram considerados os tempos de carga e descarga. Não foram considerados demais tempos que envolvem a estadia de um navio, como tempo de espera para atracação e desatracação, pois estes sofrem influência de fatores externos que não dependem do terminal, como mudanças de programação da empresa em função do mercado, mau tempo, etc. Este recurso está relacionado com o nível de serviço. O tempo é medido em horas.

Para a mão de obra foi considerado o número de técnicos de operação que trabalham em cada terminal. Os técnicos de operação executam ou fazem parte da maioria das tarefas não administrativas em um terminal, como todo o procedimento da chegada do navio no porto até sua desatracação para saída, medição e amostragem dos tanques do terminal e do navio, verificação da documentação e equipamentos do navio, controle do funcionamento dos equipamento etc. Além dos operadores, também fazem parte das operações dos navios no terminal: técnicos de segurança, inspetores independentes, fiscais da receita e auxiliares de amarração, práticos e agentes. Essas funções não apresentam variação do número de pessoas de um terminal para outro ou não são desempenhadas por funcionários do terminal, portanto a desconsideração destes não influenciou no resultado. Este fator está relacionado com os recursos humanos. A medida é absoluta

O número de berços representa a disponibilidade do terminal em receber o navio conforme a programação e a demanda do mercado. Em função de atrasos no carregamento ou das condições das marés, os navios podem sofrer alterações em suas chegadas ou saídas. Esse fator representa a flexibilidade do terminal em atender às demandas geradas na alteração da programação. Este recurso está relacionado com recurso investimento de capital. A medida é absoluta.

A quantidade movimentada é o volume de produtos carregados e descarregados e representa a necessidade do terminal em atender ao mercado. 
O volume que cada terminal carrega ou descarrega é determinado mensalmente pela gerência responsável pelo planejamento logístico da empresa e depende de fatores externos, como demanda do mercado, produção das refinarias, volume de produtos importados e exportados. A medida é em metros cúbicos.

A Tabela 3 apresenta os valores dos insumos e produtos que foram usados na análise de cada terminal. Os dados foram normalizados na base 100 para manter o sigilo dos dados da empresa.

\begin{tabular}{lrrrr}
\hline \multicolumn{3}{c}{ Insumo } & Produto \\
\hline Terminal & Tempo de & Número de & $\begin{array}{c}\text { Número de } \\
\text { Operços }\end{array}$ & $\begin{array}{c}\text { Quantidade. } \\
\text { Movimentada }\end{array}$ \\
& Operadores & Beros & 3,5 \\
T1 & 17,2 & 25,5 & 50,0 & 1,4 \\
T2 & 4,2 & 7,6 & 50,0 & 7,0 \\
T3 & 21,5 & 23,6 & 25,0 & 25,8 \\
T4 & 66,9 & 66,0 & 100,0 & 1,5 \\
T5 & 6,8 & 32,0 & 75,0 & 41,2 \\
T6 & 78,2 & 95,3 & 100,0 & 8,9 \\
T7 & 52,3 & 48,1 & 75,0 & 5,6 \\
T8 & 43,4 & 40,6 & 50,0 & 4,5 \\
T9 & 22,2 & 76,4 & 25,0 & 3,5 \\
T10 & 13,6 & 23,6 & 25,0 & 12,9 \\
T11 & 34,7 & 100,0 & 50,0 & 16,2 \\
T12 & 57,0 & 38,7 & 100,0 & 100,0 \\
T13 & 77,0 & 86,8 & 100,0 & 14,1 \\
T14 & 100,0 & 51,9 & 75,0 & 23,6 \\
T15 & 31,8 & 37,7 & 25,0 & 1,1 \\
T16 & 5,6 & 73,6 & 25,0 & \\
\hline
\end{tabular}

Tabela 1- Insumos e produtos dos terminais Fonte: Banco de Dados da Empresa

\subsection{3.}

\section{Definição do Modelo}

A definição do modelo DEA BCC está de acordo com as conclusões de Cullinane et al. (2006), pois existem diferenças de escala entre os terminais selecionados. A orientação ao insumo justifica-se, pois um aumento da quantidade movimentada não é uma decisão gerencial dos terminais, uma vez que dependerá também do consumo de combustíveis do mercado no qual o terminal se encontra. Visa-se verificar quais terminais melhor utilizam os seus insumos básicos. Esta escolha está de acordo com a teoria de análise da 
eficiência operacional conforme apresentada por Cullinane et al. (2006) e Wang et al. (2003).

Além do modelo DEA BCC clássico, neste estudo a eficiência também foi analisada pelo método da fronteira invertida, pois possibilita uma comparação entre os terminais eficientes, evita as distorções em relação aos terminais falsos eficientes e caracteriza os terminais por suas piores práticas gerenciais.

\section{2.}

\section{Cenário do Modelo}

No modelo proposto será analisada uma empresa do setor petroquímico com 12 refinarias que são ligadas a 49 terminais marítimos e terrestres. Os terminais são administrados por uma operadora logística, responsável pelo abastecimento de petróleo a estas refinarias e pelo escoamento da produção de derivados.

A maior parte das refinarias se encontra na região Sudeste, sendo necessária a movimentação de derivados às demais regiões do país. A produção de derivados destas refinarias não é suficiente para abastecer a toda demanda do país, por isso, além da produção nacional, é necessária a importação de derivados.

\subsection{1. \\ Descrição dos terminais analisados}

Nos próximos parágrafos é feita uma descrição de cada terminal analisado. Os nomes dos terminais foram ocultados por motivo de sigilo de informação empresarial.

T1 - Abastece dois estados da região Norte. O píer do terminal é público. Recebe derivados claros, Gás Liquefeito de Petróleo (GLP) e combustível marítimo. Abastece quatro terminais de companhias distribuidoras de combustível e três de companhias distribuidoras de GLP. Também fornece combustível marítimo para os navios comerciais.

T2 - Escoa derivados de petróleo (diesel, gasolina e combustível marítimo), recebidos por navios, e álcool, por caminhões-tanque, para suprir as demandas energéticas de um estado da região Nordeste e das áreas de abrangência. Atende a três terminais de companhias distribuidoras de combustível e fornece combustível marítimo para os navios comerciais. 
T3 - Tem por função principal servir de ponto de armazenagem e de escoamento, por meio de cabotagem ou por viagens de longo curso, para a produção de petróleo oriundo dos campos terrestres na região Nordeste. Movimenta nafta e diesel recebidos por navios ou provenientes de uma refinaria e abastece quatro terminais de companhias distribuidoras de combustível.

T4 - Realiza operações de cabotagem, de importação e de exportação de produtos claros, escuros e de petróleo, facilitando o escoamento dos diversos produtos de/para uma refinaria na região Sudeste. Também abastece navios comerciais com combustível marítimo.

T5 - Recebe gasolina e diesel de navio. Além destes, recebe petróleo dos campos de produção. Envia petróleo para refinarias de outros estados e abastece dois terminais de companhias distribuidoras de combustível da região nordeste. Através do modal rodoviário, recebe álcool que é armazenado e expedido por navios para exportação.

T6 - Recebe petróleo, carrega e descarrega derivados por navio. Principal ponto de escoamento da produção de uma refinaria, cujos derivados abastecem as regiões Norte e Nordeste. Abastece uma empresa petroquímica, companhias distribuidoras locais e também fornece combustível aos navios comerciais.

T7 - Recebe por navios e barcaças com petróleo, GLP e derivados claros e escuros para uma refinaria na região Norte. Abastece as companhias distribuidoras e termelétricas locais, além de realizar importação e exportação para os países Andinos.

T8 - Movimenta em seu píer navios com petróleo, lubrificantes e derivados de petróleo para uma refinaria na região Nordeste. Abastece duas companhias distribuidoras de combustível e duas companhias distribuidoras de glp. Fornece combustível para os navios comerciais.

T9 - Terminal interligado com uma refinaria na região Sul por modais rodoviário e ferroviário para escoamento de derivados escuros. Para derivados claros, utiliza um poliduto bidirecional. Recebe derivados importados por cabotagem e é um dos principais fornecedores de combustíveis marítimos.

T10 - Recebe diesel e bunker para o mercado local. Fornece combustível para os navios comerciais e realiza exportação de diesel para os países platinos.

T11 - Opera como elemento regulador do estoque da produção de derivados; transfere e recebe de navios; recebe e expede para uma refinaria na região Sudeste e para um terminal terrestre que atende a mais duas refinarias, envia por dutos para duas companhias distribuidoras de GLP. Também abastece os navios comerciais com combustível marítimo. 
T12 - Recebe e armazena derivados de petróleo e GLP. Atende a cinco terminais de distribuidoras de combustível e três de distribuidoras de glp. O transporte de derivados nacionais faz com que o terminal atue como entreposto de importação e de cabotagem para terminais de menor porte, além de fornecer combustível marítimo para os navios comerciais.

T13 - Dentre os terminais, é o que movimenta a maior quantidade em volume de produtos, recebe petróleo e derivados de importação. Exporta petróleo. Carrega derivados para abastecer demais regiões do país e abastece quatro refinarias na região sudeste. Ponto de abastecimento de combustível marítimo para os navios comerciais.

T14 - Atende a quatro terminais de distribuidoras de combustível e cinco distribuidoras de GLP na região Nordeste. Recebe derivados de petróleo por navio. Atende também a uma empresa de petroquímica e fornece combustível marítimo para os navios comerciais.

T15 - Terminal oceânico não abrigado, constituído por dois sistemas de monoboias instalados em mar aberto, na região Sul. As monoboias são projetadas para a amarração de navios nas operações de carga e de descarga de petróleo e derivados (nafta, diesel, condensado petroquímico e gasolina). 0 terminal atende a uma refinaria e a uma petroquímica por um gasoduto.

T16 - Recebe gasolina e diesel por navio e abastece as empresas distribuidoras na região Sudeste. O terminal opera óleo combustível para as indústrias locais e abastece navios com combustível marítimo. O píer deste terminal é propriedade de outra companhia, que também opera com produto a granel. 


\section{6. Apresentação e Análise dos Resultados Encontrados.}

Neste capítulo, apresentaremos a classificação dos terminais quanto à sua eficiência e quais fatores contribuíram para que se atingisse esse resultado. Além disso, serão avaliados quais terminais podem ser referência para os terminais não eficientes. Finalmente, determina-se que metas podem ser alcançadas para estes terminais não eficientes.

A aplicação do método DEA foi realizada por meio do Sistema Integrado de Apoio à Decisão - SIAD, desenvolvido por Angulo-Meza et al. (2005). A versão utilizada é o SIAD v3.0. O SIAD já foi utilizado em outros trabalhos acadêmicos (Sousa Júnior et al., 2013; Cortez et al., 2013; Bertoloto e Soares de Mello, 2011), tendo propiciado resultados satisfatórios com o método DEA, o que justifica seu emprego no presente estudo.

Com os resultados das eficiências e dos pesos, foi resolvido um problema de programação linear pelo programa AIMMS v3.13, desenvolvido por Bisschop (2013), visando a análise dos pesos nulos.

\section{1. \\ Classificação quanto à eficiência.}

$\mathrm{Na}$ Tabela 4 é possível verificar quais terminais foram considerados eficientes. Além da classificação clássica, também é apresentada a classificação composta, em que, além de se classificar os terminais pelas melhores práticas, classifica-se também aqueles que não realizam as piores práticas.

$\mathrm{Na}$ Tabela 4 são apresentadas quatro eficiências: a eficiência padrão, que define quais terminais são eficientes, e é encontrada de acordo com o sistema de equações (38) à (42); a eficiência invertida, que é encontrada pelo método da fronteira invertida e é apresentado no sistema de equações (69) à (73); a eficiência composta que é a média aritmética da eficiência em relação à fronteira clássica e o complemento da ineficiência em relação a fronteira invertida e é apresentada na fórmula (74) e a eficiência normalizada, que é encontrada através da divisão de todos os valores pelo maior índice calculado 
De acordo com a Tabela 4, conclui-se que os terminais: T3, T15, T10, T2, T9, T13 e T16 são eficientes, pois atingiram o valor de eficiência máxima: 1. No intuito de analisar qual melhor de todos, verifica-se, pela eficiência composta, que o terminal T3 apresentou o melhor resultado. Observa-se também que, apesar dos terminais T9, T13 e T16 serem classificados como eficientes, quando se observa sua eficiência invertida, estes terminais possuem um elevado grau de características negativas. Isto ocorre, pois em DEA a eficiência é vista de modo otimista. Já quando verificamos pela fronteira invertida estes terminais, embora eficientes, também têm grau máximo naqueles insumos que utilizam mal.

Os terminais T2, T3, T9, T10, T15 e T16 atingiram a eficiência por possuírem os menores insumos. O terminal T2 possui o menor tempo de operação e os demais terminais têm menor número de berços.

\begin{tabular}{lcccc}
\hline Terminal & $\begin{array}{c}\text { Eficiência } \\
\text { Padrão }\end{array}$ & $\begin{array}{c}\text { Eficiência } \\
\text { Invertida }\end{array}$ & $\begin{array}{c}\text { Eficiência } \\
\text { Composta }\end{array}$ & $\begin{array}{c}\text { Eficiência } \\
\text { Normalizada }\end{array}$ \\
\hline T3 & 1 & 0,44 & 0,78 & 1 \\
T15 & 1 & 0,45 & 0,77 & 0,99 \\
T10 & 1 & 0,54 & 0,73 & 0,94 \\
T2 & 1 & 0,75 & 0,63 & 0,80 \\
T9 & 1 & 1 & 0,50 & 0,64 \\
T13 & 1 & 1 & 0,50 & 0,64 \\
T16 & 1 & 1 & 0,50 & 0,64 \\
T1 & 0,69 & 0,73 & 0,48 & 0,62 \\
T5 & 0,64 & 1 & 0,32 & 0,41 \\
T8 & 0,55 & 1 & 0,27 & 0,35 \\
T11 & 0,54 & 1 & 0,27 & 0,35 \\
T12 & 0,54 & 1 & 0,27 & 0,34 \\
T6 & 0,51 & 1 & 0,25 & 0,32 \\
T4 & 0,48 & 1 & 0,24 & 0,31 \\
T14 & 0,48 & 1 & 0,24 & 0,31 \\
T7 & 0,45 & 1 & 0,22 & 0,29 \\
\hline
\end{tabular}

Tabela 2- Classificação por Eficiência dos Terminais Fonte: Autor

\section{2.}

\section{Pesos atribuídos aos fatores de cada terminal}

Na Tabela 5, é possível observar que o fator de escala $\left(u^{*}\right)$ é positivo para os terminais eficientes, logo, trabalham com retorno crescente de escala, isto significa que um aumento dos insumos provocaria um aumento mais que proporcional da capacidade de produção. A exceção é o terminal T13, que 
apresentou um fator de escala nulo, ou seja, trabalha com retorno de escala constante.

Conforme apresentado na Tabela 5, os terminais que apresentaram valores de peso nulo para os insumos $\left(v_{i}\right)$ ou para a quantidade movimentada $\left(u_{j}\right)$ atingiram a eficiência considerando somente os demais fatores, ou seja, estes insumos ou produtos com pesos de valor igual a zero não tiveram importância para que a eficiência fosse atingida.

\begin{tabular}{|c|c|c|c|c|c|}
\hline $\begin{array}{l}\text { Pesos / } \\
\text { Terminais }\end{array}$ & $\begin{array}{l}\text { Tempo de } \\
\text { Operação }\end{array}$ & $\begin{array}{l}\text { Número de } \\
\text { Operadores }\end{array}$ & $\begin{array}{c}\text { Número } \\
\text { de Berços }\end{array}$ & $\begin{array}{c}\text { Quantidade } \\
\text { Movimentada }\end{array}$ & $\begin{array}{c}\text { Fator de } \\
\text { Escala }\end{array}$ \\
\hline $\mathrm{T} 1$ & 0,007 & 0,014 & 0,010 & 0,016 & 0,631 \\
\hline T2 & 0,239 & - & - & 0,177 & 0,745 \\
\hline T3 & - & 0,028 & 0,013 & 0,024 & 0,831 \\
\hline T4 & - & 0,010 & 0,003 & 0,010 & 0,232 \\
\hline T5 & 0,083 & - & 0,006 & 0,064 & 0,543 \\
\hline T6 & 0,008 & 0,001 & 0,003 & 0,008 & 0,170 \\
\hline T7 & - & 0,012 & 0,005 & 0,010 & 0,353 \\
\hline T8 & - & 0,014 & 0,009 & - & 0,545 \\
\hline T9 & - & - & 0,040 & - & 1,000 \\
\hline T10 & 0,039 & 0,004 & 0,015 & 0,038 & 0,865 \\
\hline T11 & 0,016 & 0,002 & 0,006 & 0,016 & 0,334 \\
\hline T12 & - & 0,014 & 0,005 & 0,013 & 0,319 \\
\hline $\mathrm{T} 13$ & - & - & 0,010 & 0,010 & - \\
\hline T14 & - & 0,013 & 0,004 & 0,013 & 0,299 \\
\hline T15 & - & - & 0,040 & 0,039 & 0,074 \\
\hline T16 & 0,045 & 0,005 & 0,016 & 0,045 & 0,949 \\
\hline
\end{tabular}

Tabela 3-- Peso das Variáveis

Fonte: Autor

Como existe mais de uma possibilidade de conjunto de pesos para que o terminal observado atinja a eficiência, foi realizada uma maximização dos pesos nulos encontrados, a fim de verificar realmente se este insumo não foi considerado pelo terminal que está sendo observado. Este recurso foi utilizado por Alves e Soares de Mello (2015) e Soares de Mello et al. (2013)

A maximização é apresentada no sistema de equações (75) à (80)

$$
\operatorname{Max}\left(\operatorname{Min} v_{i}\right) \text { ou } \operatorname{Max}\left(\operatorname{Min} u_{j}\right)
$$

Sujeito a: 


$$
\begin{aligned}
& \sum_{j \in J} u_{j} y_{j o}-u_{*}-E f f_{o} \cdot \sum_{i \in I} v_{i} x_{i o}=0 \\
& \sum_{j \in J} v_{i} x_{i o}=1 \\
& \sum_{j \in J} u_{j} y_{j k}-\sum_{i \in I} v_{i} x_{i k}-u_{*} \leq 0, \forall k \\
& v_{i} \geq 0, \forall i \in I \\
& u_{j} \geq 0, \forall j \in J \\
& \text { em que: }
\end{aligned}
$$

$\mathrm{K}: \quad$ conjunto dos terminais $(1, \ldots, \mathrm{s})$

I: $\quad$ conjunto dos insumos $\mathrm{i}(1, \ldots, \mathrm{n})$

$\mathrm{J}: \quad$ conjunto dos produtos $\mathrm{j}(1, \ldots, \mathrm{m})$

$\mathrm{x}_{\mathrm{ik}}$ : insumo i para o terminal $\mathrm{k}$

$\mathrm{y}_{\mathrm{jk}}$ : $\quad$ produto j para o terminal $\mathrm{k}$

$\mathrm{x}_{\mathrm{io}}$ : insumo i para terminal observado

$\mathrm{y}_{\mathrm{jo}}: \quad$ produto j para terminal observado

$\mathrm{v}_{\mathrm{i}}$ : $\quad$ peso dado ao insumo $\mathrm{i}$

$\mathrm{u}_{\mathrm{j}}$ : $\quad$ peso dado ao produto $\mathrm{j}$

$u_{*} \quad$ fator de escala

Eff $_{\circ}$ eficiência calculada para o terminal observado

A equação (76) garante que a eficiência calculada seja mantida para todos os conjuntos de pesos encontrados. A equação (77) garante que o somatório dos inputs virtuais seja igual a 1. Finalmente, a equação (78) garante que a eficiência da DMU sob análise não seja maior que 1, quando utilizados os pesos ótimos da DMU observada.

O problema de programação linear (PPL) foi resolvido com auxílio do software AIMMS 3.13 (Bisschop, 2013).

Os resultados do PPL (75) indicaram que os valores de pesos nulos são máximos para todos os terminais ineficientes e para o terminal eficiente T9, o que indica folgas nas variáveis analisadas e que o terminal T9 é fracamente eficiente.

Depois de comprovados os valores máximos nulos de cada peso, conforme Alves e Soares de Mello (2015), é possível associar os pesos à importância das variáveis, caso os dados sejam tratados. A contribuição absoluta de cada variável é encontrada pela multiplicação do valor normalizado 
da variável com o peso que a DMU atribuiu a esta variável. Os valores da importância de cada variável para os terminais podem ser vistos na Tabela 6

A Tabela 6 apresenta os resultados encontrados para a importância relativa de cada variável para os terminais:

\begin{tabular}{ccccc}
\hline $\begin{array}{c}\text { Contribuição } \\
\text { / Terminais }\end{array}$ & Tempo & $\begin{array}{c}\text { Número de } \\
\text { Operadores }\end{array}$ & $\begin{array}{c}\text { Número de } \\
\text { Berços }\end{array}$ & $\begin{array}{c}\text { Quantidade } \\
\text { Movimentada }\end{array}$ \\
\hline T1 & 0,12 & 0,36 & 0,52 & 0,06 \\
T2 & 1,00 & - & - & 0,25 \\
T3 & - & 0,68 & 0,32 & 0,17 \\
T4 & - & 0,66 & 0,34 & 0,25 \\
T5 & 0,57 & - & 0,43 & 0,10 \\
T6 & 0,64 & 0,08 & 0,28 & 0,34 \\
T7 & - & 0,59 & 0,41 & 0,09 \\
T8 & - & 0,56 & 0,44 & - \\
T9 & - & - & 1,00 & - \\
T10 & 0,53 & 0,10 & 0,36 & 0,13 \\
T11 & 0,56 & 0,17 & 0,28 & 0,21 \\
T12 & - & 0,53 & 0,47 & 0,22 \\
T13 & - & - & 1,00 & 1,00 \\
T14 & - & 0,67 & 0,33 & 0,18 \\
T15 & - & - & 1,00 & 0,93 \\
T16 & 0,26 & 0,35 & 0,39 & 0,05 \\
\hline
\end{tabular}

Tabela 4- Importância Relativa das Variáveis

Fonte: Autor

Conforme se pode observar pela Tabela 6, o tempo de operação não foi um fator decisivo para a eficiência da maioria dos terminais comparado ao número de berços, que foi mais considerado, ou seja, o tempo de operação não pode ser considerado como uma boa prática para a maioria dos terminais em relação a suas eficiências.

Apesar de os terminais T3 e T10 serem eficientes por estar no grupo que tem o menor número de berços, este fator não foi o único de grande importância para estes terminais atingirem a eficiência. Como se pode observar na Tabela 6, o terminal T3 atribuiu um valor de maior importância para a variável de número de operadores. Já o terminal T10 atribui maior importância para a variável de tempo de operação. Isso mostra que estes terminais também apresentam boas práticas nestes fatores. 
Neste estudo, estas folgas ocorreram nos terminais: T4, T7, T8, T12 e T14 para o tempo de operação e no terminal T5 para o número de operadores. É possível verificar estas folgas para o tempo de operação pela Figura 6.

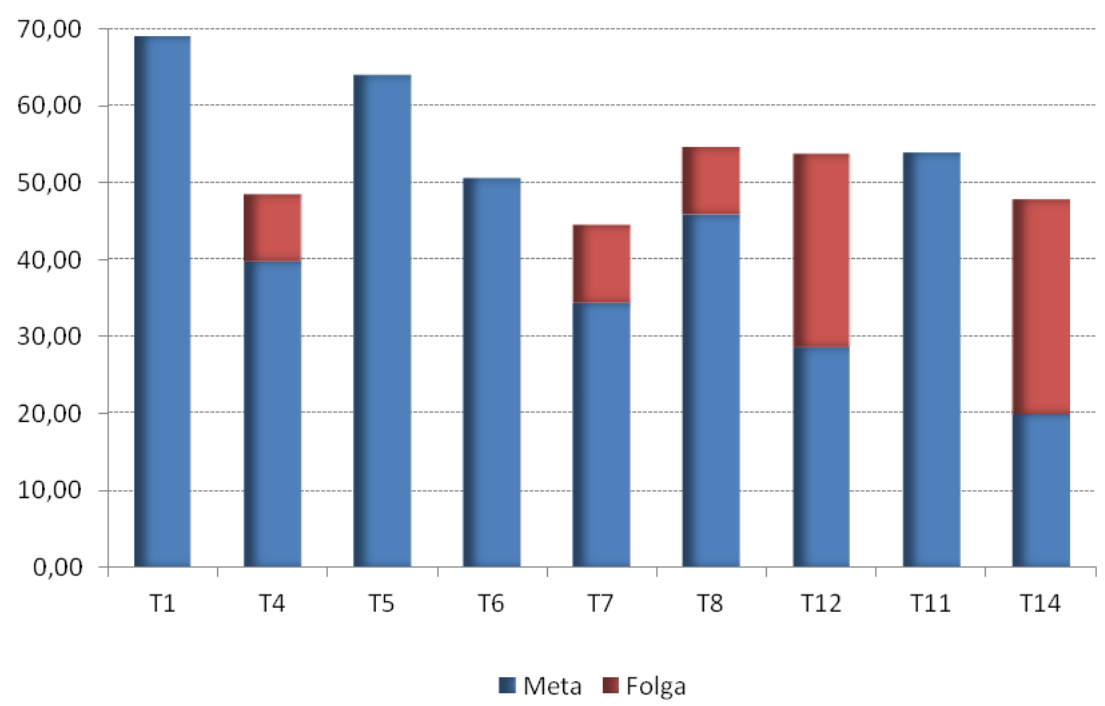

Figura 6- Metas para o Tempo de Operação

Fonte: Autor

Na Figura 7 são apresentadas as metas para redução do número de operadores.

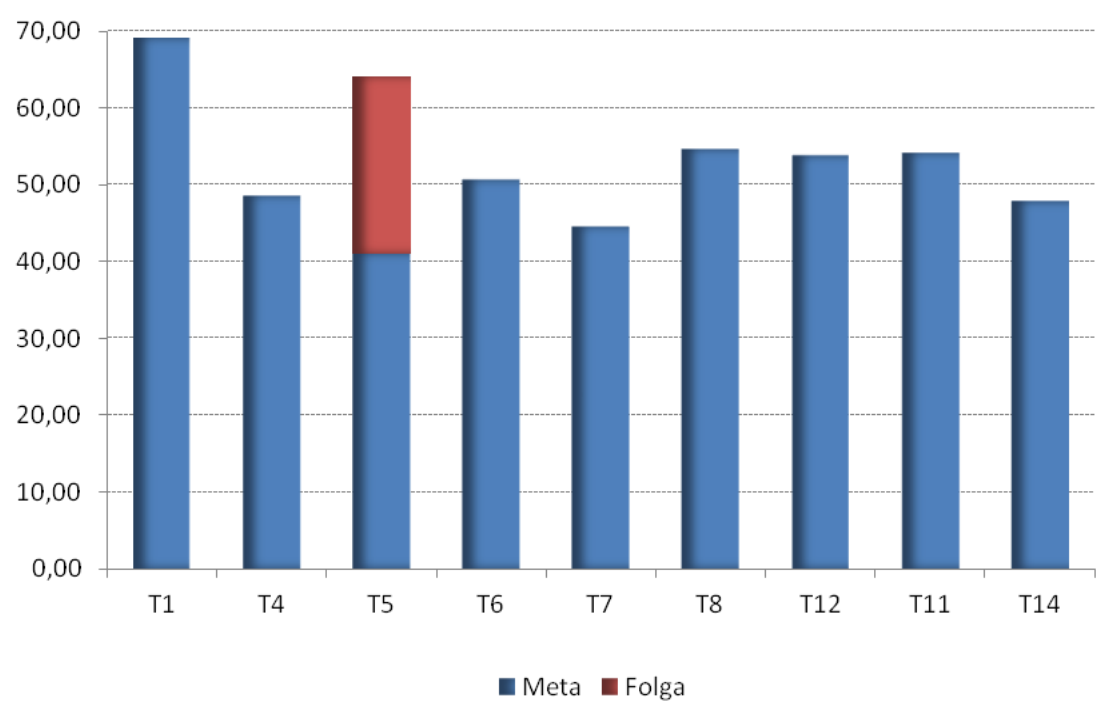

Figura 7- Metas para o número de operadores

Fonte: Autor 
O terminal T4 deverá reduzir o seu número de operadores para $48,4 \%$ do total atual. O terminal T5 deverá reduzir o número de operadores a $64 \%$ do total de operadores. Caso se deseje ser mais restritivo, deve-se eliminar a folga existente, reduzindo o número de operadores a $41 \%$ do total.

$\mathrm{Na}$ Figura 8 são apresentadas as metas para redução do número de berços. Para esta variável, observa-se que não houve folgas, logo as metas a serem alcançadas por cada terminal ineficiente estão relacionadas diretamente com sua eficiência padrão.

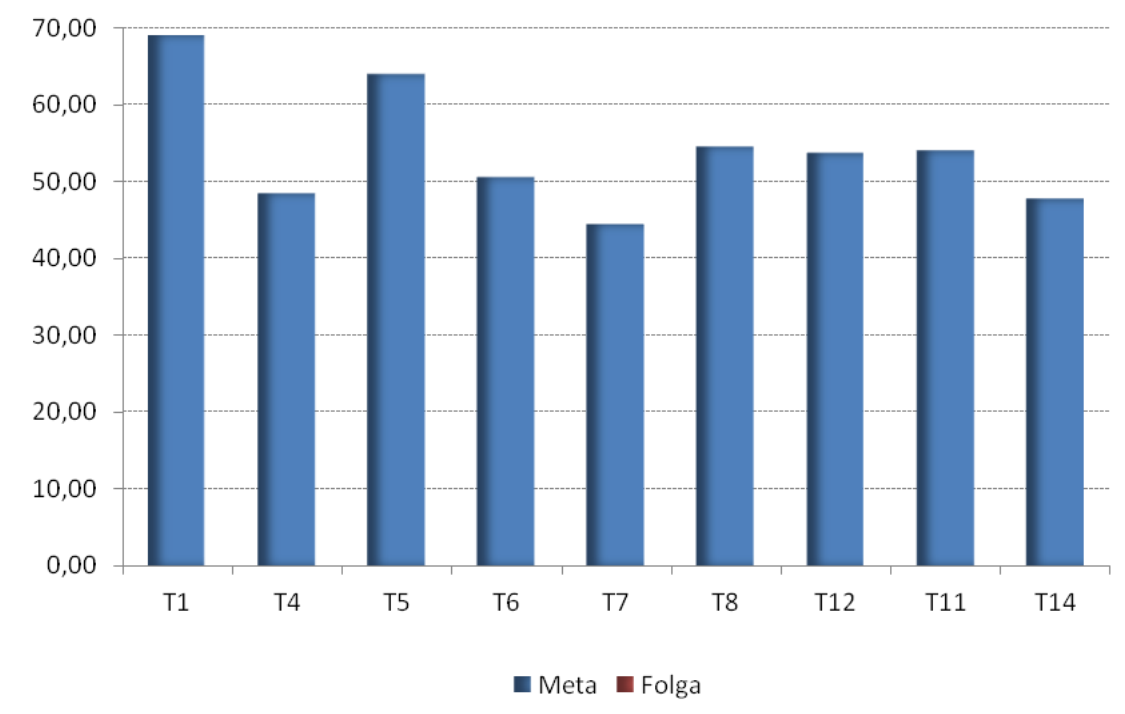

Figura 8 - Metas para o número de berços

Fonte: Autor

\section{5 .}

\section{Considerações:}

Os três terminais da região Sul, dois da região Sudeste e apenas dois da região Nordeste foram considerados eficientes. Nenhum dos dois terminais da região Norte analisados atingiram a eficiência. Dos sete terminais eficientes quatro estão diretamente relacionados a uma refinaria

Dos sete terminais da região Nordeste, apenas dois foram considerados eficientes. Uma das razões dos terminais T8, T12 e T14 terem baixa eficiência, deve-se à característica de realizar a operação de descarga direta nos tanques das companhias distribuidoras, ocorrendo a necessidade de interrupções na operação devido à troca de companhia distribuidora, sendo que algumas apresentam restrição de vazão. Além disso, o terminal T8 utiliza um píer público. 
Devido a não prioridade de utilização deste píer a operação pode ser interrompida e realizada em mais de uma fase.

Já o terminal T6 apresenta uma grande extensão de área, o que torna necessária uma demanda maior de mão de obra. Para o terminal T5, embora seja um terminal de pequena capacidade, há uma necessidade de que o terminal opere 24 horas em regime de turno, o que provoca uma demanda maior de mão de obra em relação à quantidade movimentada.

Dos quatro terminais da região Sudeste, dois foram considerados eficientes. Os terminais ineficientes apresentam restrições de espaço de armazenamento e/ou há necessidade de algumas operações serem realizadas diretamente para os tanques de outros terminais ou refinarias, o que aumenta a complexidade da operação.

Todos os dois terminais da região Sul foram considerados eficientes e nenhum dos dois terminais da região Norte conseguiu alcançar a eficiência. Uma das possíveis razões para a ineficiência dos terminais do norte do país deve-se à baixa vazão de operação e à realização da operação em mais de uma fase. 


\section{7. \\ Conclusão.}

Os portos são os principais elos logísticos no comércio internacional e o estudo de suas eficiências é um diferencial competitivo para o desenvolvimento de um país. Neste contexto, os terminais de combustível são o principal elo entre as refinarias, as indústrias petroquímicas e as distribuidoras de combustível. Dentre as técnicas utilizadas para medir essa eficiência destaca-se a técnica Data Envelopment Analysis (DEA).

Apesar de a literatura indicar a metodologia DEA para análise da eficiência dos terminais e portos, a maioria dos estudos encontrados analisa os portos como um todo considerando todos os tipos de carga e movimentação ou foram feitos somente para terminais que movimentam contêineres. Poucos estudos foram feitos considerando somente os terminais a granel.

Este estudo apresentou um caso empírico de análise da eficiência de terminais de carga líquida que operam petróleo e seus derivados utilizando a técnica DEA. Foi utilizado o modelo BCC com orientação ao insumo, pois pretendia verificar-se quais terminais usam melhor seus recursos, isto é, são enxutos.

Neste estudo foram considerados 16 terminais que movimentam petróleo e seus derivados. Para analisar a eficiência, os terminais foram comparados entre si, em relação a sua quantidade movimentada, ao número de operadores, ao número de berços e ao tempo de carga e descarga.

Concluiu-se que três terminais da região Sul, dois da região Sudeste e dois da região Nordeste foram considerados eficientes. Os dois terminais da região Norte analisados não atingiram a eficiência. Destes sete terminais eficientes, quatro estão diretamente relacionados a uma refinaria.

Através da técnica de Fronteira Invertida, classificou-se o terminal T3, na região Nordeste, com melhor resultado para eficiência. $\mathrm{O}$ terminal T2, da região Nordeste, foi referência para a maior parte dos terminais que não foram considerados eficientes.

Através da maximização dos pesos nulos das variáveis, confirmou-se que o terminal T9 é fracamente eficiente e as variáveis, mais críticas para os terminais ineficientes. 
Dentre os três insumos que foram analisados, o tempo de operação não foi considerado por um maior número de terminais no cálculo de sua eficiência. Por outro lado, estes terminais apresentaram uma elevada pontuação em sua eficiência pela fronteira invertida caracterizando uma má gestão no tempo de operação, o que representa uma oportunidade de melhoria na qualidade do atendimento e redução de custos como sobre-estadia.

Entre os motivos que provocam esse aumento nos tempos dos terminais estão: o procedimento de carga ou descarga ser realizado em mais de uma fase, a vazão reduzida de operação, a falta de espaço para armazenamento nos tanques e a complexidade em suas operações.

As metas a serem alcançadas por cada terminal não eficiente são proporcionais a sua eficiência. Assim, os terminais não eficientes devem reduzir seus insumos entre $30 \%$ a $50 \%$ com uma média de $45 \%$.

O uso do método proposto pode ser utilizado pela operadora logística da empresa na administração de seus recursos humanos e pela empresa na avaliação da infraestrutura e qualidade do serviço usado para atender a seus clientes.

A utilização do modelo é importante pelo fato de fornecer um índice de como são usados os fatores de produção do ponto de vista de recursos humanos, infraestrutura e qualidade de serviço, como pôde ser visto no presente estudo.

Para estudos futuros, sugere-se que uma análise com modelos de DEA com variáveis não controladas isto é, em casos em que os alvos para essas variáveis sejam inviáveis como espaço em tanque.

Além disso, sugere-se comparar os terminais eficientes deste estudo com outros terminais internacionais, para que se possa verificar o grau de eficiência dos terminais nacionais frente a uma concorrência estrangeira. 


\section{8. Referências bibliográficas}

ACCARIO, M. The role of ports in the development of Mediterranean islands: the case of Sardinia. International Journal of Transport Economics, v.35, n.3, p.295-323, 2008.

ACOSTA, C.M.M.; SILVA, A.M.V.A.; LIMA, M.L.P. Aplicação de análise envoltória de dados (DEA) para medir eficiência em portos brasileiros. Journal of Transport Literature, v.5, n.4, p.88-102, 2011.

ADLER, N.; FRIEDMAN, L.; SINUANY-STERN, Z. Review of ranking methods in the data envelopment analysis context. European Journal of Operations Research, v.140, p.249-265, 2002.

ALVES, L.A.; SOARES DE MELLO, J.C.C.B. Weights based clustering in Data Envelopment Analysis using Kohonen Neural Network: an application in Brazilian electrical sector. IEEE Latin America Transactions, v.13, n.1, p.188-194, 2015.

ANGULO-MEZA, L.; BIONDI NETO, L.; SOARES DE MELLO, J.C.C.B; E GOMES, E.G. ISYDS-Integrated System for Decision Support (Sistema Integrado de Apoio à Decisão - SIAD): a software package for data envelopment analysis model. Pesquisa Operacional, v.25, n.3, p.493-503, 2005.

ANGULO-MEZA, L.; GOMES, E.G.; SOARES DE MELLO, J.C.C.B.; BIONDI NETO, L. Fronteira DEA de dupla envoltória no estudo da evolução da ponte aérea Rio-São Paulo. Panorama Nacional da Pesquisa em Transportes, v.2, p.1158-1166, 2003.

ANGULO-MEZA, L.; LINS, M.P.E. Review of methods for increasing discrimination in Data Envelopment Analysis. Annals of Operations Research, v.116, n.1-4, p.225-242, 2002.

ANGULO MEZA, L.; SOARES DE MELLO, J.C.C.B.; GOMES, E.G. FERNANDES, A. J. S. Seleção de variáveis em DEA aplicada a uma análise do mercado de energia elétrica. Investigação Operacional, v.27, n.1, p.21-36, 2007.

ANP - Agência Nacional de Petróleo - Dados estatísticos mensais. Disponível em:

<http://www.anp.gov.br/?pg=69299\&m=\&t1=\&t2=\&t3=\&t4=\&ar=\&ps=\&cachebust $=1426605095843>$. Acesso em 10 março 2015 .

ANTAQ - Agência Nacional de Transportes Aquaviários - Relatório de Navegação Marítima e de Apoio, 2014.

BANKER, R.D.; CHARNES, A.; COOPER, W.W. Some models for estimating technical and scale inefficiencies in data envelopment analysis. Management Science, v.30, n.9, p.1078-1092, 1984.

BANKER, R.D.; CHARNES, A.; COOPER, W.W.; SWARTS, J.; THOMAS, D. An introduction to data envelopment analysis with some of its models and their uses. Research in Government and Nonprofit Accounting, v.5, p.125-163, 1989. 
BARROS, C.P. Incentive regulation and efficiency of Portuguese port authorities. Maritime Economics and Logistics, v.5, n.1, p.55-69, 2003a.

BARROS, C.P. The measurement of efficiency of Portuguese sea port authorities with DEA. International Journal of Transport Economics, v.30, n.3, p.335-354, 2003b.

BARROS, C.P.; ATHANASSIOU, M. Efficiency in European seaports with DEA: evidence from Greece and Portugal. Maritime Economics \& Logistics, v.6, n.2, p.122-140, 2004.

BARROS, C.P.; FELICIO, A.; FERNANDES, R.L. Productivity analysis of Brazilian Seaports. Maritime Policy \& Management, v.39, n.5, p.503-523, 2012.

BERTOLOTO, R.F.; SOARES DE MELLO, J.C.C.B. Eficiência de portos e terminais privativos brasileiros com características distintas. Journal of Transport Literature, v.5, n.2, p.4-21, 2011.

$\mathrm{BICHOU}, \mathrm{K}$. Review of port performance approaches and a supply chain framework to port performance benchmarking. Research in Transportation Economics, v.17, p.567-598, 2007.

$\mathrm{BICHOU}, \mathrm{K}$. An empirical study of the impacts of operating and market conditions on container-port efficiency and benchmarking. Research in Transportation Economics, v.42, p.28-37, 2013.

BICHOU, K.; GRAY, R. A critical review of conventional terminology for classifying seaports. Transportation Research Part A: Policy and Practice, v.39, n.1, p.75-92, 2005.

BISSCHOP, J. AIMMS Optimization Modeling. Paragon Decision Technology, 2013.

BONILLA, B.; CASASUS, T.; MEDAL, A.; SALA, R. An efficiency analysis with tolerance of the Spanish port system. International Journal of Transport Economics, v.31, n.3, p.379-400, 2004.

BRASIL. Constituição da República Federativa do Brasil de 5 de outubro de 1988. Decreto 6620/08 - Políticas e Diretrizes para Portos e Terminais Portuários.

Disponível em: <http://presrepublica.jusbrasil.com.br/legislacao/93005/decreto6620-08>. Acesso em 17 março 2015.

CASTRO, J.V.; COTO MILLAN, P. Port economic impact: Methodologies and applications to the port of Santander. International Journal of Transport, v.25, n.2, p.159-179, 1998.

CHARNES, A.; COOPER, W.W.; GOLANY, B.; SEIFORD, L.; STUTZ, J. Foundations of data envelopment analysis for Pareto-Koopmans efficient empirical production functions. Journal of Econometrics, v.30, p.91-107, 1985.

CHARNES, A.; COOPER, W.W.; LEWIN, A.Y.; SEIFORD, L.M. Data envelopment analysis: theory, methodology, and application. Dordrecht: Kluwer Academic, 1994. 513p.

CHARNES, A.; COOPER, W.W.; RHODES, E.L. Measuring the efficiency of decision making units. European Journal of Operational Research, v.2, p.429444, 1978.

CHARNES, A.; COOPER, W.W.; RHODES, E.L. Evaluating program and managerial efficiency: An application of data envelopment analysis to program follow through. Management Science, v.27, p.668-697, 1981. 
CHARNES, A.; COOPER, W.W.; THRALL, R.M. A structure for classifying and characterizing efficiency and inefficiency in data envelopment analysis. The Journal of Productive Analysis, v.2, p.197-237, 1991.

COELLI, T.J. A multi-stage methodology for the solution of orientated DEA models. Operations Research Letters, v. 23, p.143-149, 1998.

COELLI, T.J.; RAO, D.S.P.; O'DONNELL, C.J.; BATTESE, G.E. An introduction to efficiency and productivity analysis. 2ed. Springer, 2005. $275 p$.

COOK, W.D.; SEIFORD, L.M. Data Enevelopment Analysis (DEA) - Thirty years on. European Journal of Operation Research, v.192, p.1-17, 2009.

COOK, W.D.; TONE, K.; ZHU, J. Data envelopment analysis: Prior to choosing a model. Omega, v.44, p.1-4, 2014.

COOPER, W.; SEIFORD, L.M.; TONE, K. Introduction to data envelopment analysis and its uses. Ed. Springer, 2006. 354p.

COOPER, W.; SEIFORD, L.M.; ZHU, J. Handbook on Data Envelopment Analysis. 2ed. Ed. Springer, 2011. 495p.

CORTEZ, L.C.S.; OLIVEIRA, L.R.D.; MARTINS, E.F.; JESUS, I.R.D.D.; SOARES DE MELLO, J.C.C.B. Análise de eficiência na gestão de portos públicos brasileiros em relação ao papel das autoridades portuárias. Journal of Transport Literature, v.7, n.2, p.78-96, 2013.

CULLINANE, K.P.B.; JI, P.; WANG, T.-F. The relationship between privatization and DEA estimates of efficiency in the container port industry. Journal of Economics and Business, v.57, n.5, p.433-462, 2005a.

CULLINANE, K.P.B.; SONG, D.-W.; JI, P.; WANG, T.-F. An application of DEA windows analysis to container port production efficiency. Review of Network Economics, v.3, n.2, p.186-208, 2004.

CULLINANE, K.P.B.; SONG, D.-W.; WANG, T.-F. The application of mathematical programming approaches to estimating container port production. Journal of Productivity Analysis, v.24, n.1, p. 73-92, 2005b.

CULLINANE, K.P.B.; WANG, T.-F. The efficiency of European container ports: a cross-sectional data envelopment analysis. International Journal of Logistics: Research and Applications, v.9, n.1, p.19-31, 2006.

CULLINANE, K.P.B.; WANG, T.-F.; SONG, D.-W.; JI, P. The technical efficiency of container ports: comparing data envelopment analysis and stochastic frontier analysis. Transportation Research Part A: Policy and Practice, v.40, p.354-374, 2006b.

DEBREU, G. The measurement of Productive Efficiency. Econometrica, v.19, n.3, p.273-292, 1951.

DOYLE, J.; GREEN, R. Efficiency and cross-efficiency in DEA derivations, meanings and uses. Journal of the Operational Research Society, v.45, p.567-578, 1994.

DUTRA, A.; RIPOLL-FELIU, V.M.; FILLOL, A.G.; ENSSLIN, S.R.; ENSSLIN, L. The construction of knowledge from the scientific literature about the theme seaport performance evaluation. International Journal of Productivity and Performance Management, v.64, n.2, p.243-269, 2015. 
DYSON, R.G.; ALLEN, R.; CAMANHO, A.S.; PODINOVSKI, V.V.; SARRICO, C.S.; SHALE, E.A. Pitfalls and protocols in DEA. European Journal of Operational Research, v.132, p.242-259, 2001.

EMROUZNEJAD, A.; PARKER, B.R.; TAVARES, G. Evaluation of research in efficiency and productivity: a survey and analysis of the first 30 years of scholarly literature in DEA. Socio-Economic Planning Sciences, v.42, p.151-157, 2008.

ENTANI, T.; MAEDA, Y.; TANAKA, H. Dual models of interval DEA and its extensions to interval data. European Journal of Operational Research, v.136, p.32-45, 2002.

ENTANI, T.; TANAKA, H. Improvement of efficiency intervals based on DEA by adjusting inputs and outputs. European Journal of Operational Research, v.172, p.1004-1017, 2006.

FARRELL, M.J. The measurement of technical efficiency. Journal of the Royal Statistics Society, Series A (General), Part III, v.120, n.3, p.253-290, 1957.

FONTES, O.H.P.M.; SOARES DE MELLO, J.C.C.B. Avaliação da eficiência portuária através de uma modelagem DEA. Anais do SPOLM 2006 - X Simpósio de Pesquisa Operacional e Logística da Marinha, Rio de Janeiro, RJ, 2006.

FOURGEAUD, F. Measuring port performance. Washington, DC: The World Bank. 2000.

GALVÃO, C.B.; ROBLES, L.T.; GUERISE, L.C. The Brazilian seaport system: a post-1990 institutional and economic review. Research in Transportation Business \& Management, v.8, p.17-29, 2013.

GOLANY, B.; ROLL, Y. An application procedure for DEA. Omega, v.17, n.3, p.237-250, 1989.

GONZÁLEZ, M.M.; TRUJILLO, L. Efficiency measurement in the port industry: A survey of the empirical evidence. Journal of Transport Economics and Policy (JTEP), v.43, n.2, p.157-192, 2009.

GUERRERO, J.I.F.; SELVA, L.M.; MEDINA, R.P. Economic impact of Western Mediterranean leisure ports. International Journal of Transport Economics, v.35, n.2, p.251-272, 2008.

ITOH, H. Efficiency changes at major container ports in Japan: A window application of data envelopment analysis. Review of Urban and Regional Development Studies, v.1, n.2, p.133-152, 2002.

KOOPMANS, T.C., Activity Analysis of Production and Allocation., John Wiley \& Sons, New York, 1951

LAWRANCE, D.; RICHARDS, A. Distributing the gains from waterfront productivity improvements. Economic Record, v.80, n.s1, p.S43-S52, 2004.

LETA, R.F.; SOARES DE MELLO, J.C.C.B.; GOMES, E.G.; ANGULO MEZA, L. Métodos de melhora de ordenação em DEA aplicados à avaliação estática de tornos mecânicos. Investigação Operacional, v.25, p.229-242, 2005.

LI, X.B.; REEVES. G.R. A multiple criteria approach to data envelopment analysis. European Journal of Operational Research, v.115, p.507-517, 1999.

LINS, M.P.E.; ANGULO-MEZA, L. Análise envoltória de dados e perspectivas de integração no ambiente de apoio à decisão. Editora da COPPE/UFRJ, Rio de Janeiro, 2000. 232p 
LINS, M.P.E.; DE LYRA NOVAES, L.F.; LEGEY, L.F.L. Real estate appraisal: A double perspective data envelopment analysis approach. Annals of Operations Research, v.138, n.1, p.79-96, 2005.

LINS, M.P.E.; MOREIRA, M.C.B. Método IO stepwise para seleção de variáveis em modelos de análise envoltória de dados. Pesquisa Operacional, v.19, n.1, p.39-50, 1999.

LIU, J.S.; LU, L.Y.Y.; LU, W.M.; LIN, B.J.Y. Data envelopment analysis 19782010: a citation-based literature survey. Omega, v.41, p.3-15, 2013a.

LIU, J.S.; LU, L.Y.Y.; LU, W.M.; LIN, B.J.Y. A survey of DEA applications. Omega, v.41, p.893-902, 2013b.

LOFTI, F.H.; JAHANSHAHLOO, G.R.; KHODABAKHI, M.; MALKHLIFEH, M.R.; MOGHADDAS, Z.; GHASEMI, M.V. A review of ranking models in DEA. Journal of Applied Mathematics, 2013.

MACIEL, G.S.; LIMA, G.B.A.; ANGULO-MEZA, L.; GOMES JÚNIOR, S.F. Avaliação de processos licitatórios de embarcações de apoio marítimo offshore com utilização de análise envoltória de dados. Journal of Transport Literature, v.8, n.4, p.329-349, 2014.

MARTIN, M. El sistema portuario español: Regulacion, entorno competitivo y resultados. Una aplicacion del analisis envolvente de datos. 2002. Ph.D. Thesis - Universitat Rovira I Virgili, Tarragona, Espanha. 2002.

MARTINEZ-BUDRIA, E.; ARMAS, R.D.; IBAFIEZ, M.I.; MESA, T.R. A study of the efficiency of Spanish port authorities using data envelopment analysis, International Journal of Transport Economics, v.26, n.2, p.237-253, 1999.

MDIC - Ministério do Desenvolvimento Indústria e Comércio - Dados consolidados da balança comercial brasileira de 2014. Disponível em: $<$ http://www.mdic.gov.br//sitio/interna/interna. php?area $=5 \&$ menu=4761 $>$. Acesso em 10 março 2015.

MERK, O.; DANG, T. Efficiency of world ports in container and bulk cargo (oil, coal, ores and grain). OECD Regional Development Working Papers 2012/9, OECD Publishing, 2012.

OLIVEIRA, G.F.; CARIOU, P.A DEA study of the efficiency of 122 iron ore and coal ports of $15 / 17$ countries in 2005. Maritime Policy \& Management, v.38, n.7, p.727-743, 2011.

PALLIS, A.A.; VITSOUNIS, T.K.; DE LANGEN, P.W. Port economics, policy and management: Review of an emerging research field. Transport Reviews, v.30, n.1, p.115-161, 2010.

PANAYIDES, P.M.; MAXOULIS, C.; WANG, F.-T.; NG, K.Y.A. A critical analysis of DEA applications to seaport economic efficiency measurement. Transport Reviews, v.29, n.2, p.183-206, 2009.

PARETO, V. Manuel d'Economie Politique. Giars \& Briere, Paris, 1909

PARK, K.R.; DE, P. An alternative approach to efficiency measurement of seaports. Maritime Economics \& Logistics, v.6, n.1, p.53-69, 2004.

PIRES, L.S.; BERTOLOTO, R.F.; SOARES DE MELLO, J.C.C.B. Análise da eficiência de portos de carregamento de minério de ferro. Rio's International Journal on Sciences of Industrial and Systems Engineering and Management, v.3, 2009. 
PIZZOLATO, N.D.; SCAVARDA, L F.; PAIVA, R. Zonas de influência portuáriashinterlands: Conceituação e metodologias para sua delimitação. Gestão e Produção, v.17, n.3, p.553-566, 2010.

RIOS, L.R.; MAÇADA, A.C.C. Analyzing the relative efficiency of container terminals of Mercosur using DEA. Maritime Economics \& Logistics, v.8, n.4, p.331-346, 2006.

RODRIGUES, P.R.A. Introdução aos sistemas de transporte no Brasil e à logística internacional. 4ed. Edições Aduaneiras Ltda, 2011.

ROLL, Y.; HAYUTH, Y. Port performance comparison applying data envelopment analysis (DEA). Maritime Policy \& Management, v.20, n.2, p.153-161, 1993.

SENRA, L.F.A.C.; NANCI, L.C.; SOARES DE MELLO, J.C.C.B.; ANGULO MEZA, L. Estudo sobre métodos de seleção de variáveis em DEA. Pesquisa Operacional, v.27, n.2, p.191-207, 2007.

SEXTON, T.R.; SILKMAN, R.H.; HOGAN, A.J. Data envelopment analysis: Critique and extensions. In: SILKMAN, R.H. (Ed.) Measuring efficiency: An assessment of data envelopment analysis. New Directions for Program Evaluation, n.32. San Francisco: Jossey-Bass, Winter 1986. p.73-105.

SHARMA, M.J.; YU, S.J. Performance based stratification and clustering for benchmarking of container terminals. Expert Systems with Applications, v.36, n.3, p.5016-5022, 2008.

SOARES DE MELLO, J.C.C.B.; ANGULO MEZA, L.; BIONDI NETO, L.; GOMES, E.G. Curso de análise de envoltória de dados. SBPO 2005 - XXXVII Simpósio Brasileiro de Pesquisa Operacional, Gramado, RS, 2005.

SOARES DE MELLO, J.C.C.B.; ANGULO-MEZA, L.; GOMES, E.G.; FERNANDES, A.J.S.; BIONDI NETO, L. Estudo não paramétrico da relação entre consumo de energia, renda e temperatura. IEEE Latin America Transactions, v.6, n.2, p.153-161, 2008a.

SOARES DE MELLO, J.C.C.B.; ANGULO MEZA, L; SILVEIRA, J.Q. ; GOMES, E.G. About negative efficiencies in cross evaluation BCC input oriented models. European Journal of Operational Research, v.229, p.732-737, 2013.

SOARES DE MELLO, J.C.C.B. ; GOMES, E.G.; ANGULO-MEZA, L.; LETA, F.R. DEA Advanced Models for Geometric Evaluation of used Lathes. WSEAS Transactions on systems, v.7, n.5, p.500-520, 2008b.

SOARES DE MELLO, J.C.C.B.; GOMES, E.G.; SOARES DE MELLO, M.H.C.; LINS, M.P.E. Método multicritério para seleção de variáveis em modelos DEA. Revista Pesquisa Naval, v.15, p.55-66, 2002.

SOUSA JÚNIOR, J.N.C.; PRATA, B.A.; NOBRE JÚNIOR, E.F.; SOARES DE MELLO, J.C.C.B. Análise da eficiência dos portos utilizando análise de envoltória de dados: Estudo de caso da região Nordeste do Brasil. Journal of Transport Literature, v.7, n.4, p.75-106, 2013.

TALLURI S.; SARKIS, J. Extensions in efficiency measurement of alternate machine component grouping solutions via data envelopment analysis. IEEE Transactions on Engineering Management, v.44, p.27-31, 1997.

TONGZON, J. Efficiency measurement of selected Australian and other international ports using data envelopment analysis. Transportation Research Part A: Policy and Practice, v.35, n.2, p.107-122, 2001. 
TOVAR, A.C.A.; FERREIRA, G.C.M. A infraestrutura portuária Brasileira: O modelo atual e perspectivas para seu desenvolvimento sustentado. Revista do BNDES, v.13, n.25, p.209-230, 2006.

TURNER, H.; WINDLE, R.; DRESNER, M. North American containerport productivity: 1984-1997. Transportation Research Part E: Logistics and Transportation Review, v.40, n.4, p.339-356, 2004.

UNCTAD - United Nations Conference on Trade and Development. Review of maritime transport, 2012.

UNCTAD - United Nations Conference on Trade and Development. Review of maritime transport, 2014.

VALENTINE, V. F.; GRAY, R. The measurement of port efficiency using data envelopment analysis. Proceedings of the 9th World Conference on Transport Research, Seoul, July 2001. p.22-27.

Wang, T.-F. and Cullinane, K.P.B. The efficiency of European container terminals and implications for supply chain management, Maritime Economics \& Logistics, v. 8, n.1, p.82-99, 2006.

WANG, T.-F.; CULLINANE, K.; SONG, D.-W. Container port production efficiency: A comparative study of DEA and FDH approach. Journal of the Eastern Asia Society for Transportation Studies, v.5, p.698-713, 2003.

WANG, T.-F.; SONG, D.-W.; CULLINANE, K.P.B. The applicability of data envelopment analysis to efficiency measurement of container ports. Proceedings of the International Association of Maritime Economists Conference, Panama, November 2002. p.13-15.

WANKE, P.F.; Physical infrastructure and shipment consolidation efficiency drivers in Brazilian ports: A two-stage network-DEA approach. Transport Policy, v.29, p.145-153, 2013.

WANKE, P.F.; BARBASTEFANO, R.G.; HIJJAR, M. F. Determinants of efficiency at major Brazilian port terminals. Transport Reviews, v.31, n.5, p.653-677, 2011.

WANKE, P.F.; MATTOS, R. Capacity issues and efficiency drivers in Brazilian bulk terminals. Brazilian Business Review, v.11, n.5, p.72-98, 2014.

WOO, S.H.; PETTIT, J.S.; KWAK, D.W.K.; BERESFORD, K.C. Seaport research: A structured literature review on methodological issues since 1980s. Transportation Research Part A: Policy and Practice, v.45, n.7, p.667-685, 2011.

WU, J.Y.C.; GOH, M. Container port efficiency in emerging and more advanced markets. Transportation Research Part E: Logistics and Transportation Review, v.46, n.6, p.1030-1042, 2010.

YAMADA, Y.; MATUI, T.; SUGIYAMA, M. New analysis of efficiency based on DEA. Journal of the Operations Research Society of Japan, v.37, n.2, p.158167, 1994. 